\title{
Computation of liquid-liquid equilibria and phase stabilities: implications for RH-dependent gas/particle partitioning of organic-inorganic aerosols
}

\author{
A. Zuend ${ }^{1,2}$, C. Marcolli ${ }^{2}$, T. Peter ${ }^{2}$, and J. H. Seinfeld ${ }^{1}$ \\ ${ }^{1}$ Department of Chemical Engineering, California Institute of Technology, 91125, Pasadena, California, USA \\ ${ }^{2}$ Institute for Atmospheric and Climate Science, ETH Zurich, 8092, Zurich, Switzerland
}

Received: 4 May 2010 - Published in Atmos. Chem. Phys. Discuss.: 12 May 2010

Revised: 17 August 2010 - Accepted: 19 August 2010 - Published: 24 August 2010

\begin{abstract}
Semivolatile organic and inorganic aerosol species partition between the gas and aerosol particle phases to maintain thermodynamic equilibrium. Liquid-liquid phase separation into an organic-rich and an aqueous electrolyte phase can occur in the aerosol as a result of the saltingout effect. Such liquid-liquid equilibria (LLE) affect the gas/particle partitioning of the different semivolatile compounds and might significantly alter both particle mass and composition as compared to a one-phase particle. We present a new liquid-liquid equilibrium and gas/particle partitioning model, using as a basis the group-contribution model AIOMFAC (Zuend et al., 2008). This model allows the reliable computation of the liquid-liquid coexistence curve (binodal), corresponding tie-lines, the limit of stability/metastability (spinodal), and further thermodynamic properties of multicomponent systems. Calculations for ternary and multicomponent alcohol/polyol-water-salt mixtures suggest that LLE are a prevalent feature of organic-inorganic aerosol systems. A six-component polyol-water-ammonium sulphate system is used to simulate effects of relative humidity ( $\mathrm{RH})$ and the presence of liquid-liquid phase separation on the gas/particle partitioning. RH, salt concentration, and hydrophilicity (water-solubility) are identified as key features in defining the region of a miscibility gap and govern the extent to which compound partitioning is affected by changes in $\mathrm{RH}$. The model predicts that liquid-liquid phase separation can lead to either an increase or decrease in total particulate mass, depending on the overall composition of a sys-
\end{abstract}

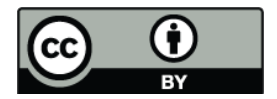

Correspondence to: A. Zuend (zuend@ caltech.edu) tem and the particle water content, which is related to the hydrophilicity of the different organic and inorganic compounds. Neglecting non-ideality and liquid-liquid phase separations by assuming an ideal mixture leads to an overestimation of the total particulate mass by up to $30 \%$ for the composition and RH range considered in the six-component system simulation. For simplified partitioning parametrizations, we suggest a modified definition of the effective saturation concentration, $C_{j}^{*}$, by including water and other inorganics in the absorbing phase. Such a $C_{j}^{*}$ definition reduces the $\mathrm{RH}-$ dependency of the gas/particle partitioning of semivolatile organics in organic-inorganic aerosols by an order of magnitude as compared to the currently accepted definition, which considers the organic species only.

\section{Introduction}

Primary aerosol particles, directly emitted to the atmosphere, and secondary aerosol, formed by gas-to-particle conversion, undergo chemical and physical processing during their lifetime, resulting in a mixture of organic and inorganic aerosol species (Maria et al., 2004; Kanakidou et al., 2005; Aumont et al., 2005). Single particle measurements suggest that organic and inorganic species are internally mixed in particulate matter (PM), except for air masses close to local sources (Murphy and Thomson, 1997; Middlebrook et al., 1998; Lee et al., 2002; Murphy et al., 2006). Internal mixing of organics and inorganics is established by gas phase diffusion (Marcolli et al., 2004b) and partitioning between the gas phase and particle phases driving the system towards thermodynamic equilibrium. 
While the most prevalent inorganic aerosol components are well established (Zhang et al., 2007; Russell et al., 2009), the organic fraction can consist of a large number of different compounds (Goldstein and Galbally, 2007), containing functional groups such as alkyl, hydroxyl, carboxyl, carbonyl, and aromatic groups (Rogge et al., 1993; Saxena and Hildemann, 1996; Yu et al., 1999; Decesari et al., 2000; Griffin et al., 2002; Decesari et al., 2006; Russell et al., 2009). Non-ideal interactions between organic and inorganic species in the liquid aerosol phase affect water uptake (Saxena et al., 1995; Clegg et al., 2001; Zuend et al., 2008), may induce phase separation (Pankow, 2003; Erdakos and Pankow, 2004; Chang and Pankow, 2006; Marcolli and Krieger, 2006), affect efflorescence and deliquescence behaviour (Choi and Chan, 2002; Chan and Chan, 2003; Pant et al., 2004; Parsons et al., 2004; Marcolli and Krieger, 2006; Ling and Chan, 2008), and influence the gas/particle partitioning of semivolatile compounds (Saxena and Hildemann, 1997; Turpin et al., 2000; Cocker et al., 2001; Seinfeld et al., 2001; Bowman and Melton, 2004; Chang and Pankow, 2006). Moreover, liquid and solid phases present in aerosol particles provide reaction media for heterogeneous and multiphase chemistry (Ravishankara, 1997; Kalberer et al., 2004; Barsanti and Pankow, 2004; Knopf et al., 2005; Herrmann et al., 2005; Kroll and Seinfeld, 2008). At least in the lower troposphere, most of the organic aerosol (OA) fraction is expected to be present in liquid form even at low relative humidity (RH), because the large number of organic compounds depresses the temperature at which solids form (Marcolli et al., 2004a).

The gas/particle partitioning of a specific compound depends on the ambient conditions (temperature, RH), its vapour pressure and on the concentrations and vapour pressures of all other particle-phase species, and the manner in which they interact (non-ideality). These factors determine whether an organic compound resides primarily in the gas phase, primarily in the particulate phase, or to a significant degree in both phases. Following Pankow (2003), at temperature $T$, partitioning of compound $j$ can be expressed in terms of a molar $(n)$ particle/gas equilibrium coefficient $K_{j}^{\mathrm{PM},(n)}$ :

$K_{j}^{\mathrm{PM},(n)}=\frac{R T}{p_{j}^{\circ} \gamma_{j}^{(x)}}$,

where $R$ is the universal gas constant, $p_{j}^{\circ}$ the pure liquid compound vapour pressure, and $\gamma_{j}^{(x)}$ the mole fraction-based activity coefficient. Details and assumptions involved in the derivation of Eq. (1) are given in Sect. 3.1. From Eq. (1), two of the most prominent sources of uncertainties in modelling the gas/particle partitioning of complex, often multifunctional organic compounds are evident (Hallquist et al., 2009; Barley and McFiggans, 2010): (1) potentially large errors in estimating pure compound vapour pressures ( $p_{j}^{\circ}$ as a function of $T$ ) in the absence of actual measurements and (2) un- certainty in describing liquid phase non-ideality, represented by $\gamma_{j}^{(x)}$, and related effects, such as liquid-liquid phase separations. A third major uncertainty, endemic to modelling of atmospheric organic aerosols, is the lack of knowledge of the actual molecular composition of the aerosol phase (the “ $j$ "s). In this study, we focus on a systematic reduction of uncertainties related to issue (2) by means of modelling phase behaviour and gas/particle partitioning of non-ideal solutions typical of these present in atmospheric organicinorganic aerosols.

Thermodynamic models are essential for the computation of phase diagrams and gas/particle partitioning of organicinorganic mixtures. Such models help to understand and link data from different experimental techniques and to predict thermodynamic properties for multicomponent mixtures. Models have been developed for calculating the partitioning of organics into an organic aerosol particle (Pankow et al., 2001), as well as for organics and water into an aqueous organic solution (Seinfeld et al., 2001). So far, only a few models have been reported that are able to predict gas/particle partitioning of mixed organic-inorganic systems (Pun et al., 2002; Griffin et al., 2003; Chang and Pankow, 2006, 2010; Pankow and Chang, 2008). The model of Pun et al. (2002) uses a so called hydrophobic-hydrophilic approach, characterizing the particulate matter in terms of a hydrophobic organic phase and a hydrophilic aqueous phase, allowing an organic compound to partition only to one of the two phases. Griffin et al. (2003) modified this hydrophobichydrophilic approach to allow equilibration of all organic compounds between both condensed phases and the gas phase. However, in their approach water and salts were not allowed to partition between both condensed phases. Chang and Pankow (2006) introduced a gas/particle partitioning and activity coefficient model (XUNIFAC.2) based on the activity coefficient model LIFAC (Yan et al., 1999) and the gas/particle partitioning theory of Pankow (2003), that enables the equilibration of all species between all phases present.

We present in this work a new liquid-liquid phase separation and gas/particle partitioning model, using as a basis the group-contribution model AIOMFAC (Zuend et al., 2008). Considering the potential importance of liquid-liquid equilibria (LLE), a reliable method to check and account for phase separations has been implemented and tested with a number of ternary alcohol-water-salt solutions at room temperature. Motivated by the ability of a thermodynamic model to provide additional information regarding the stability of liquid phases, we introduce a method to compute the spinodal curves of ternary mixtures. The resulting stability diagrams allow the determination of metastable and unstable one-phase regions with respect to composition in the phase diagram. 
Liquid-liquid phase equilibria in organic-inorganic systems are typically governed by strong interactions between electrically charged ions and nonpolar organic functional groups. Resulting liquid-liquid phase separation is often referred to the salting-out effect, in which the solubility of a non-electrolyte in water is decreased when an electrolyte is added. Hydration of ions at high water content in an organicinorganic mixture attenuates the salting-out effect. Hence, liquid-liquid phase separation in aerosols is strongly influenced by the water content, and for this reason is related to the ambient RH. Barley et al. (2009) note that the RH dependency of semivolatile organic gas/particle partitioning becomes stronger with a decrease in the total concentration of organic PM. Thus, it is of interest to study the combined effects of RH and LLE on the gas/particle partitioning of semivolatile organics. For this reason, we perform a quantitative case study with a six-component organic-inorganic aerosol system, computing the gas/particle partitioning at relative humidities ranging from $20 \%$ to $99 \%$. The predictions of the equilibrium calculations (including potential LLE) are compared with the model results for a forced one-phase and for an ideal PM mixture.

Ideal condensed phase behaviour is often assumed for gas/particle partitioning descriptions in 3-D atmospheric chemical transport models, based on computation time considerations. In a number of models, gas/particle partitioning is parametrized solely in terms of an effective gas-phase saturation concentration, $C_{j}^{*}$. An unanswered question is generally the extent to which non-ideal phase behaviour in the aerosol phase and RH influence gas/particle partitioning. Regarding LLE effects on the total amount of particulate matter in comparison to the estimated PM amount assuming a single condensed phase, a common assumption is to expect an increase of PM mass, which is explained by an enhanced partitioning of hydrophobic organic compounds into an organicrich liquid phase as a result of a phase separation. Some aerosol chamber studies with relatively high total organic mass loading (organic PM typically $>50 \mu \mathrm{g} \mathrm{m}^{-3}$ ) and corresponding model results for organic aerosol systems (Griffin et al., 2003) and organic-inorganic aerosol mixtures (Chang and Pankow, 2006) confirm this LLE related effect on PM. Other studies using hypothetical aerosol systems considering polar and low-polarity organic compounds predict a PM mass increase due to liquid-liquid phase separation as well (Erdakos and Pankow, 2004; Chang and Pankow, 2006). Using AIOMFAC we reveal that for systems at lower total organic concentrations (organic $\mathrm{PM}<20 \mu \mathrm{g} \mathrm{m}^{-3}$ ) comprising organics of different hydrophilicities, liquid-liquid equilibration sometimes leads to a decrease in total PM.

\section{Theory and methods}

\subsection{Thermodynamic equilibrium}

In the context of thermodynamically describing a multicomponent mixture, the term "system" refers to a heterogeneous, closed system comprising different homogeneous phases. Each phase in a heterogeneous, closed system is characterised by its temperature $T$, pressure $p$, and the chemical potentials $\mu_{j}$ of the components present. In the absence of external forces and effects such as semi-permeable membranes, electric, magnetic, or gravitational fields, one can express the thermodynamic equilibrium of a multicomponent, multiphase system as (Modell and Reid, 1983)

$T^{\alpha}=T^{\beta}=\ldots=T^{\omega}:$ thermal equilibrium, $p^{\alpha}=p^{\beta}=\ldots=p^{\omega}$ : mechanical equilibrium, $\mu_{j}^{\alpha}=\mu_{j}^{\beta}=\ldots=\mu_{j}^{\omega}:$ chemical equilibrium,

where $\omega$ is the number of phases and $j=1,2, \ldots, k$ denotes the $k$ system components. Temperature, pressure and the chemical potentials of a system are not all independent variables. Their dependency is described by the GibbsDuhem relation and defines the Gibbs' phase rule. The total Gibbs energy $G$ of a multiphase, multicomponent system can be calculated from the molar amounts $n_{j}^{\phi}$ of the chemical species in the different phases $\phi$ and their chemical potentials $\mu_{j}^{\phi}$ :

$G=\sum_{\phi} \sum_{j} \mu_{j}^{\phi} n_{j}^{\phi}+G^{\mathrm{int}}$.

Here, $G^{\text {int }}$ represents the sum of the interfacial energies, e.g., resulting from gas-liquid and liquid-liquid interfaces. While for sufficiently small particles/phases interfacial energies can be important, we neglect their contribution in this study $\left(G^{\text {int }}=0\right)$. Thus, our model applies to systems that are dominated by bulk phases rather than interfaces and therefore also neglects curvature effects.

The Gibbs energy of a closed system in thermodynamic equilibrium is at its minimum (e.g., Denbigh, 1981; Modell and Reid, 1983). At the Gibbs energy minimum of a multiphase system at given conditions, such as a constant temperature and known overall composition, the conditions of Eq. (2) are all fulfilled. Hence, there are two options to calculate the properties of such a system in thermodynamic equilibrium. Option (1) involves solving the equality conditions of Eq. (2) by varying system parameters, such as the partitioning of the different components over coexisting phases and determining the solution with the lowest Gibbs energy. Option (2) is based on a direct search for the global minimum of the Gibbs energy of the system. Both cases can be treated as optimization problems and solved using numerical methods (e.g., Amundson et al., 2007a,b). We apply the global minimization approach and use Eq. (2) as an additional equilibrium check and precision criterion for the optimum solution. 
The methods are described in Sect. 2.4, Sect. 3, and the Appendix.

\subsection{Chemical potentials and standard states}

To calculate the Gibbs energy using Eq. (3), the chemical potentials of the different components in all coexisting phases are required. For non-electrolytes (organics, water) we use the pure $\left(x_{s}^{\circ}=1\right)$, potentially subcooled liquid at temperature $T$ on the mole fraction basis $(x)$ as reference and standard states. The chemical potentials of such non-electrolytes, here denoted as solvents $s$, in a liquid phase $l$ are

$\mu_{s}^{l}\left(p, T, x_{j}\right)=\mu_{s}^{o,(x)}+R T \ln \left[a_{s}^{(x)}\right]$,

where $\mu_{s}^{\circ,(x)}=\mu_{s}^{\circ,(x)}\left(p_{s}^{\circ}, T, x_{s}^{\circ}\right)$ is the standard chemical potential, $x_{s}$ the mole fraction of $s$ in the liquid mixture, and $a_{s}^{(x)}$ the activity on the mole fraction basis. Using the same standard states as for the liquid phase and assuming the gas phase $(g)$ to be an ideal gas mixture (no fugacity correction) with mole fractions $y_{j}$, the chemical potentials in the gas phase are given by

$\mu_{s}^{g}\left(p, T, y_{j}\right)=\mu_{s}^{\circ,(x)}+R T \ln \left[\frac{p_{s}}{p_{s}^{\circ}}\right]$.

The partial pressure $p_{s}=y_{s} p$ is related to the saturation vapour pressure over the liquid of pure $s, p_{s}^{\circ}$. The choice of the same standard chemical potential in all phases and a comparison of Eqs. (4) and (5) shows that at vapour-liquid equilibrium (VLE), liquid mixture activities and partial pressures are related by

$p_{s}=p_{s}^{\circ} a_{s}^{(x)}$.

This relation is known as the modified Raoult's law.

Electrolytes (salts, acids) in liquid mixtures are here considered to be dissociated into cations and anions. To maintain electroneutrality in the liquid phases, we combine cations and anions to the neutralized form of dissolved salt units. Such a salt unit represents an independent component in the thermodynamic sense, enabling electroneutral mass transfer between different liquid phases. For a generalised salt unit "MX" composed of $v^{+}$cations $\mathrm{M}$ and $v^{-}$anions $\mathrm{X}$ with the chemical formula $\mathrm{M}_{v^{+}} \mathrm{X}_{v^{-}}$, the chemical potential in a liquid mixture is calculated from

$\mu_{\mathrm{MX}}^{l}\left(p, T, x_{j}\right)=\mu_{\mathrm{MX}_{(\mathrm{aq})}^{\circ}}^{\circ(m)}+R T \ln \left[\left(a_{\mathrm{M}}^{(m)}\right)^{v^{+}}\left(a_{\mathrm{X}}^{(m)}\right)^{v^{-}}\right]$.

The standard chemical potential $\mu_{\mathrm{MX}_{(\mathrm{aq})}^{\circ,(m)}}^{\circ}=v^{+} \mu_{\mathrm{M}_{(\mathrm{aq})}^{\circ,(m)}}+$ $v^{-} \mu_{\mathbf{X}_{(\text {aq }}}^{\circ,(m)}$ is here defined on the molality basis, indicated by superscript $(m)$, with the reference state of an ideal, infinitely dilute aqueous solution of ion $i$ (here: $i=\mathrm{M}$ or $\mathrm{X}$ ), as defined in the AIOMFAC model (Zuend et al., 2008). The logarithm on the right-hand side of Eq. (7) contains the so-called molal ion activity product IAP:

$\operatorname{IAP}_{\mathrm{MX}}=\left(a_{\mathrm{M}}^{(m)}\right)^{\nu^{+}}\left(a_{\mathrm{X}}^{(m)}\right)^{\nu^{-}}$.

Ions are treated as nonvolatile species, therefore no gas-phase chemical potential is defined for them.

Choosing the same standard chemical potential of a species in all system phases allows us to express chemical equilibrium (Eq. 2) in terms of activities:

$a_{s}^{(x), \alpha}=a_{s}^{(x), \beta}=\ldots=a_{s}^{(x), \omega}$ : for solvents,

$\operatorname{IAP}_{M X}^{\alpha}=\operatorname{IAP}_{M X}^{\beta}=\ldots=\operatorname{IAP}_{M X}^{\omega}$ : for salt units.

This is known as the isoactivity condition, a necessary criterion for phase equilibrium in this framework. The chemical equilibrium expressions of Eq. (9) enable the calculation of liquid-liquid and vapour-liquid equilibria without having to specify the standard chemical potentials of the different system components.

\subsection{AIOMFAC model}

Equations (4), (6), (7), and (9) depend on the activities of the different species. Consequently, a model to calculate activities is required. We use the group-contribution model AIOMFAC (Aerosol Inorganic-Organic Mixtures Functional groups Activity Coefficients) of Zuend et al. (2008) to describe non-ideal mixing in liquid solutions - expressed in terms of activity coefficients. On the mole fraction basis, activity coefficients $\gamma_{s}^{(x)}$ are correction factors relating mole fractions and activities:

$a_{s}^{(x)}=\gamma_{s}^{(x)} x_{s}$.

The semi-empirical AIOMFAC model explicitly accounts for molecular interactions between solution species, both organic and inorganic. Such organic-inorganic interactions may be the cause for liquid-liquid phase separations or for enhanced partitioning of semivolatile organics to the gas phase due to salting-out effects. AIOMFAC is based on the group-contribution model LIFAC by Yan et al. (1999) - but modified to better represent relevant species, reference states, and the relative humidity range of the atmosphere. The group-contribution concept treats organic molecules as combinations of functional groups. This approach has the great advantage of representing many different compounds using a relatively small and manageable number of functional groups, such as alkyl, hydroxyl, carboxyl, carbonyl, and aromatic groups. Especially regarding the organic aerosol fraction, a compound-specific approach may not be feasible except in the case of well-defined laboratory systems.

Molecular interactions in solution, including charged and neutral species, are represented in AIOMFAC using expressions for long-range (LR), middle-range (MR), and shortrange (SR) contributions. Thus, activity coefficients are calculated from three distinct model parts:

$\ln \gamma_{s}^{(x)}=\ln \gamma_{s}^{\mathrm{LR},(x)}+\ln \gamma_{s}^{\mathrm{MR},(x)}+\ln \gamma_{s}^{\mathrm{SR},(x)}$. 
The long-range part, an extended Debye-Hückel expression, and the semi-empirical middle-range part form together a Pitzer-like (group-contribution) model, enabling accurate descriptions of electrolyte solutions, from dilute to highly concentrated (supersaturated) conditions. Short-range interactions between functional groups are calculated with the widely-used UNIFAC model (Fredenslund et al., 1975), modified to include inorganic ions and the alcohol/polyol parametrizations of Marcolli and Peter (2005). The MRpart contains most of the adjustable parameters of the model, which are estimated by fitting modelled activity coefficients to laboratory data on binary and ternary solutions. The group-contribution concept allows one to make activity coefficient predictions for solutions containing organic compounds, which were not used to estimate model parameters. At present, AIOMFAC is able to calculate activity coefficients of systems composed of a wide range of electrolytes and organic compounds with $-\mathrm{CH}_{\mathrm{n}}(n=0,1,2,3)$ and $-\mathrm{OH}$ as functional groups, all at room temperature. The AIOMFAC model framework and estimated interaction parameters are described in detail in Zuend et al. (2008).

\subsection{Computation of the liquid-liquid coexistence curve}

Liquid-liquid phase separations may occur in mixtures of two or more partially miscible components, leading to what is known as miscibility gaps; the stable thermodynamic state is referred to as the liquid-liquid equilibrium (LLE). The coexistence of two or more liquid phases at thermodynamic equilibrium implies that the total Gibbs energy of the system, gas phase plus solid and liquid particle phases (including the here neglected interfacial energies), is lower than in the case of a single liquid phase. Although, multicomponent systems might form more than two liquid phases, we restrict in this study the liquid aerosol particle to a maximum of two coexisting liquid phases. Typically one of the two liquid phases is predominantly an aqueous electrolyte solution, and the other phase contains most of the organics and, depending on their hydrophilicities, an amount of water. Figure 1a illustrates the case differentiation to diagnose a potential liquid-liquid phase separation based on the comparison of the system's Gibbs energies.

The partitioning of a species between two liquid phases, denoted as $\alpha$ and $\beta$, can be described by (Zuend, 2007):

$q_{j}^{\alpha}=\frac{n_{j}^{\alpha}}{n_{j}^{\mathrm{PM}}}$,

where $q_{j}^{\alpha}$ is the molar ratio of the fraction in phase $\alpha$ to the total PM amount of species $j$. With only two liquid PM phases it follows: $n_{j}^{\mathrm{PM}}=n_{j}^{\alpha}+n_{j}^{\beta}$ and $q_{j}^{\beta}=1-q_{j}^{\alpha}$. Using these liquid-liquid partitioning ratios with given total (liquid) PM composition in terms of mole fractions $x_{j}^{\mathrm{PM}}$, the mole fractions in the two phases are calculated by

$$
\begin{aligned}
x_{j}^{\alpha} & =\frac{q_{j}^{\alpha} x_{j}^{\mathrm{PM}}}{\sum_{k} q_{k}^{\alpha} x_{k}^{\mathrm{PM}}}, \\
x_{j}^{\beta} & =\frac{\left(1-q_{j}^{\alpha}\right) x_{j}^{\mathrm{PM}}}{\sum_{k}\left(1-q_{k}^{\alpha}\right) x_{k}^{\mathrm{PM}}},
\end{aligned}
$$

where all (liquid) PM components are included in the sum. Possible values for the liquid-liquid partitioning ratios lie within the interval of $0 \leq q_{j}^{\alpha} \leq 1$. As long as interfacial energies are negligible, Eqs. (13) and (14) show that the volume (or mass) of the two coexisting phases is not needed to define the equilibrium composition; only the distribution of the species between the phases and their mole fractions are required. For a given set of chemical components in a liquid mixture and the compositions in the phases $\alpha$ and $\beta$ from Eqs. (13) and (14), the AIOMFAC model is used to calculate the corresponding solvent activities and molal ion activity products in the phases.

The Gibbs energy of the two-phase PM system is then calculated using Eqs. (3), (4), and (7):

$G^{\mathrm{PM}}=\sum_{j} n_{j}^{\mathrm{PM}}\left(\mu_{j}^{\circ}+R T\left[q_{j}^{\alpha} \ln a_{j}^{\alpha}+q_{j}^{\beta} \ln a_{j}^{\beta}\right]\right)$.

In those cases in which component $j$ is a salt in Eq. (15), the activities and standard chemical potentials are replaced by the IAP and the standard chemical potential of the salt, respectively, according to Eq. (7). Dividing Eq. (15) by the amount of moles $\sum_{j} n_{j}^{\mathrm{PM}}$ in the PM system, we obtain an expression for the normalized (molar) Gibbs energy, $G^{*, P M}$ :

$$
\begin{aligned}
G^{*, P M}=\frac{G^{\mathrm{PM}}}{\sum_{j} n_{j}^{\mathrm{PM}}}= & \sum_{j} x_{j}^{\prime, \mathrm{PM}} \mu_{j}^{\circ} \\
& +R T \sum_{j} x_{j}^{\prime, \mathrm{PM}}\left[q_{j}^{\alpha} \ln a_{j}^{\alpha}+q_{j}^{\beta} \ln a_{j}^{\beta}\right] .
\end{aligned}
$$

Here the mole fractions $x_{j}^{\prime, P M}$ are calculated with respect to completely dissociated salts to be consistent with the activities and ion activity products obtained from AIOMFAC. The standard chemical potential of a salt and the IAP are used in Eq. (16) to calculate the contributions of salt units to the normalized Gibbs energy. Therefore, in case of dissolved salts, the mole fractions have to be calculated as mole fractions of salt units (and not of ions), but still with respect to completely dissociated salts in the mixture:

$x_{s}^{\prime, \mathrm{PM}}=\frac{n_{s}^{\mathrm{PM}}}{\sum_{j}^{n_{j}^{\mathrm{PM}}}}$ : for solvents,
$x_{\mathrm{MX}}^{\prime, \mathrm{PM}}=\frac{n_{\mathrm{MX}}^{\mathrm{PM}}}{\sum_{j}^{\mathrm{PM}} n_{j}^{\mathrm{PM}}}$ : for salt units,

where the sum goes over all mixture species, including ions. Note that the standard chemical potentials have to be known 
(a)

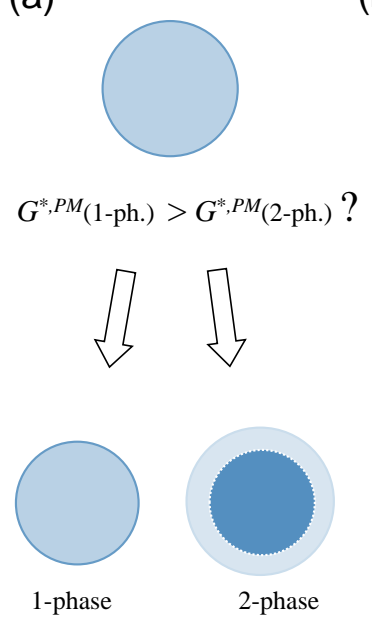

(b)

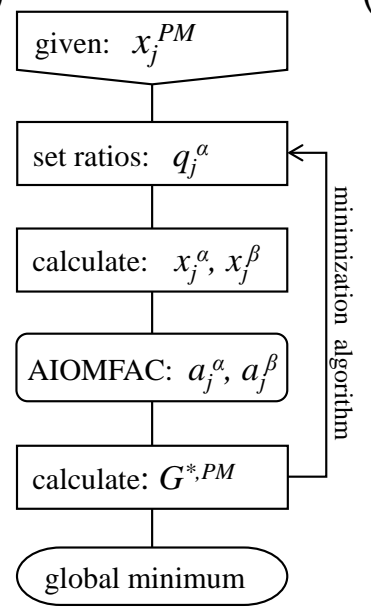

(c)

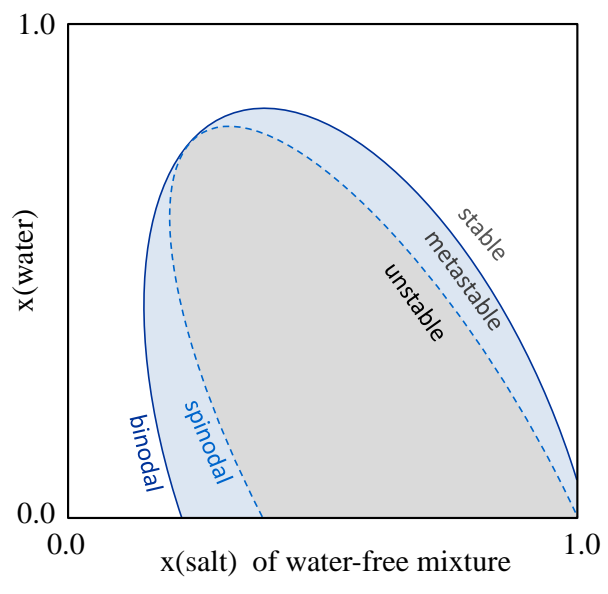

Fig. 1. (a) Illustration of the case differentiation to diagnose a potential liquid-liquid phase separation. (b) Simplified algorithm to compute the phase compositions of a two-phase system at equilibrium. AIOMFAC is called to calculate the activities in the phases. A global optimization algorithm is used to find the global minimum of $G^{*, P M}$. (c) Schematic phase diagram showing binodal and spinodal curves of a LLE and the stability of the different regions with respect to a one-phase state.

only for the calculation of a system's absolute Gibbs energy; they are not required for the LLE calculations as their contributions are the same in one- and two-phase systems. Panel (b) of Fig. 1 shows the approach to finding the compositions of coexisting phases at minimum Gibbs energy. The set of $q_{j}^{\alpha}$ is varied by a global optimization algorithm and the corresponding Gibbs energies (the objective function values) of the two-phase systems are evaluated until the set with the lowest Gibbs energy is found and the isoactivity condition is fulfilled to a certain numerical precision. In cases in which the one-phase system is stable, the algorithm finds the trivial solution of equal $q_{j}^{\alpha}$ values for all components, e.g., $q_{j}^{\alpha}=0.5$. Thus, testing against an initial set of equal $q_{j}^{\alpha}$ allows a direct objective function comparison with the onephase solution.

We use the Differential Evolution (DE) algorithm by Storn and Price (1997), a simple, efficient and robust method for global optimization. To further improve the minimum found by $\mathrm{DE}$ and to reduce overall computation time, in addition we apply the modified Powell hybrid method and the Levenberg-Marquardt method from the Fortran MINPACK library (Moré et al., 1980, 1984). Details to the use and modifications of the methods are given in Appendix A.

\subsubsection{Procedure to calculate the binodal line}

Panel (c) of Fig. 1 shows a qualitative phase diagram of a ternary mixture at constant temperature as a function of molar composition, with a liquid-liquid miscibility gap in a certain composition range. To represent three components in an orthogonal 2-D-plot, the $\mathrm{x}$-axis is here defined as mole fractions of the salt in the water-free mixture: $x$ (salt) water-free $=$ $x$ (salt, $\mathrm{w}-\mathrm{f})=n_{\text {salt }}^{\mathrm{PM}} /\left(n_{\text {org }}^{\mathrm{PM}}+n_{\text {salt }}^{\mathrm{PM}}\right)$. The procedure to calculate the binodal coexistence curve in a ternary mixture is implemented as a 2-D-scan of the composition space: (1) starting with a (low) mole fraction $x$ (salt, $\mathrm{w}$-f) on the $\mathrm{x}$-axis of the search space, (2) the mole fraction of water, the y-axis, is reduced step-by-step from high to low values while checking for a potential phase separation with the $\mathrm{DE}$ algorithm (see Appendix A) in quick mode. (3) After the lowest allowed $x$ (water) value is reached, $x$ (salt, $\mathrm{w}-\mathrm{f}$ ) is incremented by a given step size and step (2) repeated. (4) Once a phase separation is detected, DE is switched to high precision mode and a bisection in the $x$ (water) dimension of the range between the actual $x$ (water) and $x$ (water) a few steps before the phase separation (that brackets the root) is performed to detect precisely the onset of the miscibility gap, which is a locus on the binodal curve. (5) The set of corresponding $q_{j}^{\alpha}$ found is then saved and used as initial guess for the detection of the next phase separation onset, then $x$ (salt, w-f) is incremented. (6) To detect more points on the binodal curves, the scan in $x$ (water) direction can be continued at a selection of $x$ (salt, w-f) coordinates, with DE in quick mode using the $q_{j}^{\alpha}$ of the last phase separation as initial guess for the next step. This approach allows a reliable computation of the binodal curve, while advantageously handling the trade-off between computational speed and robustness of the different DE modes.

\subsubsection{An example: phase diagram of the ternary 2-propanol-water-NaCl system}

To illustrate the computation methods and the information that can be gained from the model, we consider the ternary 2-propanol-water-NaCl liquid mixture as an example. This ternary system exhibits a liquid-liquid phase separation in parts of the composition range, while the salt-free binary 

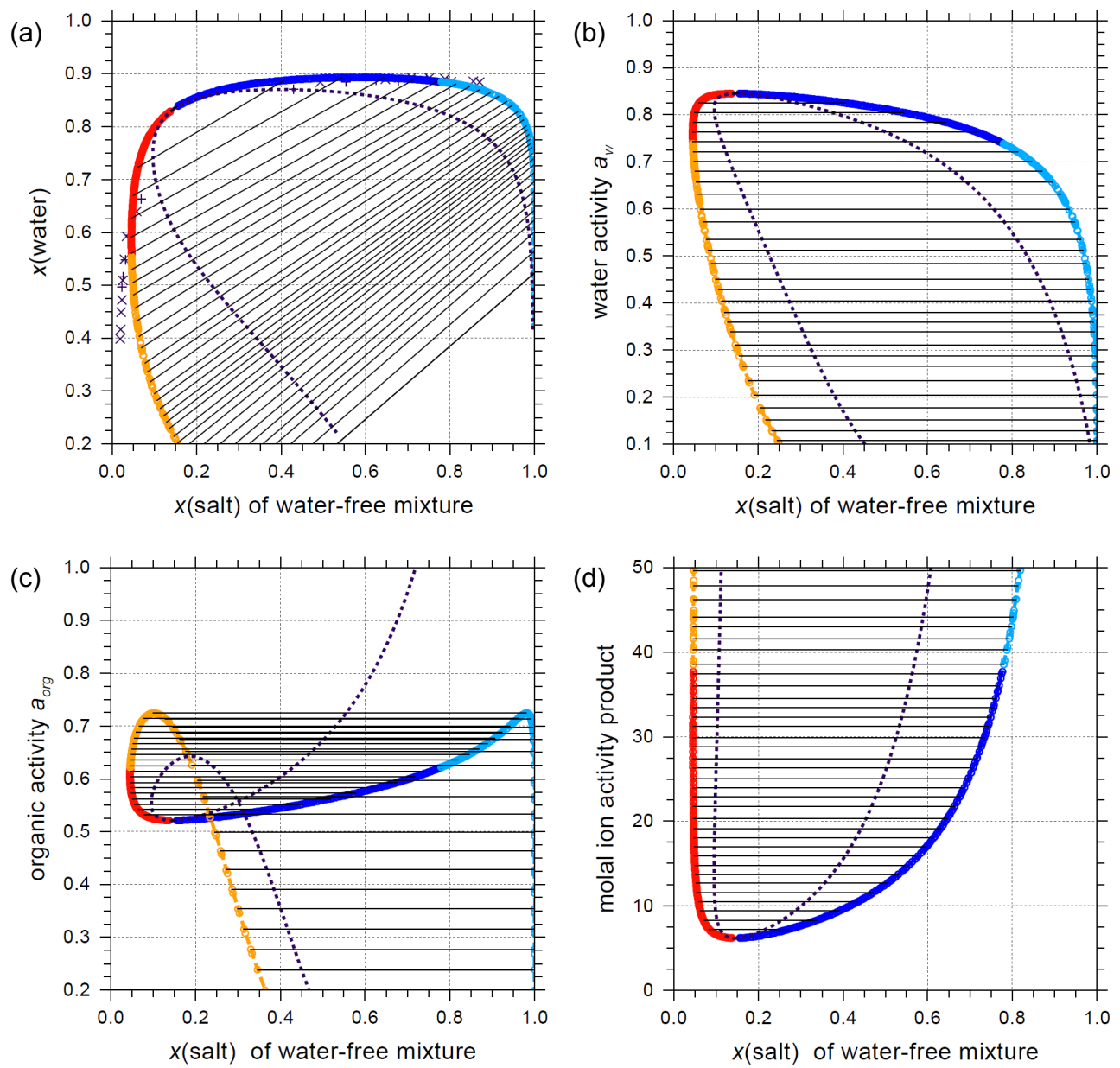

Fig. 2. Phase diagram of the ternary 2-propanol-water- $\mathrm{NaCl}$ system at room temperature $(298 \mathrm{~K})$. LLE phase composition measurements by De Santis et al. (1976), (×) and Gomis et al. (1994), (+) are shown in (a). The curves in all panels show the computed binodals and spinodals based on AIOMFAC activity coefficients. Red and blue parts of the binodal curve indicate the organic-rich phase and the aqueous electrolyte-rich phase, respectively. Orange and light blue curve parts indicate supersaturation of the phase with respect to solid NaCl. Black, straight lines indicate the coexisting phases. The spinodal is displayed as a black, dotted curve. (a) shows the mole fraction phase composition. Panels (b) and (c) show the phase diagram in terms of the different activities and (d) the molal IAP of $\mathrm{NaCl}$.

2-propanol-water solution is fully miscible at any ratio. Figure 2 shows the computed coexistence curve (binodal) of the ternary 2-propanol-water- $\mathrm{NaCl}$ phase diagram. The abscissa is defined in terms of mole fraction of the salt $(\mathrm{NaCl})$ in the water-free mixture. With regard to aerosol particles, this $\mathrm{X}$-axis can be considered as the dry particle composition. Black, straight lines connect the two coexisting phases (they are not tie-lines here, see Sect. 2.5). A description of the calculation of the limit of phase stability/metastability, the spinodal, is given in Sect. 2.6. A comparison with LLE composition measurements (De Santis et al., 1976; Gomis et al., 1994) shows that the model predicts the phase separation overall in good agreement with the experimental data. However, there are deviations, especially between measured and predicted compositions of the organic-rich phases. There are several reasons for such deviations. First, the group- contribution approach of AIOMFAC is optimized to represent organic-inorganic systems including many different alcohols/polyols composed of the same functional groups. Therefore, a specific system might not be represented perfectly by the set of interaction parameters. Second, when the AIOMFAC middle-range interaction parameters were estimated, LLE data were used with respect to relative activity deviations between the coexisting phases. Due to uncertainties associated with LLE composition measurements, optimizing modelled relative activity deviations might lead to deviations between measured and calculated compositions at liquid-liquid phase coexistence. Hence, in agreement with Marcilla et al. (2007), AIOMFAC parameters were estimated based on thermodynamic consistency. The prediction of the phase diagram in the supersaturated region with respect to solid $\mathrm{NaCl}$ might be subject to larger deviations from the real 
system behaviour as no data were available for comparison and parameter estimation at those high ionic concentrations. Typically, one would expect the deviations between the correct compositions and the AIOMFAC model predictions to increase with increasing salt content (ionic strength) and decreasing water content. The activities and the IAP of the different system components are shown in panels (b), (c), and (d) of Fig. 2. As water activity equals relative humidity in VLE and VLLE (vapour-liquid-liquid equilibria), panel (b) represents the phase diagram as a function of RH and dry composition. The phase diagram represented in terms of $x(\mathrm{NaCl})$ (water-free) and 2-propanol activity (panel c) shows a somewhat unusual curvature of the binodal and spinodal lines. Comparing Fig. 2c with Fig. 4, in which the organic activity is shown on the colour axis, allows to explain this curvature behaviour as a result of opposing interaction effects of the salt and water contents on $a_{\text {org }}$, causing a saddle point in organic activity. While in the case of water increasing either the salt concentration or the organic concentration leads to a decrease in water activity, this is obviously different for the analogous case regarding the 2-propanol activity. The branch of the spinodal curve showing a steep increase towards organic activities of 1.0 and beyond in Fig. 2c, corresponds to the spinodal curve crossing the red area in Fig. 4a (see Sect. 2.5 for a discussion of Fig. 4). The salt saturation (solubility) limit was calculated as a function of constant molal IAP based on molal salt solubility data (Apelblat and Korin, 1998). The calculated molal IAP at saturation of the corresponding binary aqueous salt solution is taken as reference value.

\subsection{Gibbs energy difference, activities, and tie-lines}

Besides the calculation of the LLE coexistence curve, we used our model to compute the Gibbs energy difference between a (forced) one-phase system and the equilibrium state system - be it a one-phase or two-phase state - covering almost the whole composition space and therefore also regions in the phase diagram, that are not accessible in experiments. We carry out a high-resolution, point-by-point computation using a similar procedure as described in Sect. 2.4.1. Figure 3 shows the Gibbs energy difference $(\Delta G)$ between a forced one-phase system and the predicted, potentially two-phase, equilibrium of the ternary 2-propanol-water- $\mathrm{NaCl}$ system. The formation of solid $\mathrm{NaCl}$ at saturation is disabled to allow for salt supersaturation. The $\Delta G$ "hill" represents the energy needed to maintain an unfavourable, metastable or unstable state of a one-phase system. As a result of the point-by-point computation of the phase diagram, additional information is obtained, such as the activities of all species for the equilibrium solution and for a (hypothetical) one-phase solution at each point in composition space (even when absolutely unstable). Using this information, we calculate contour lines of constant water activity with respect to the equilibrium state. Thus, starting initially at a point in the two-phase region of
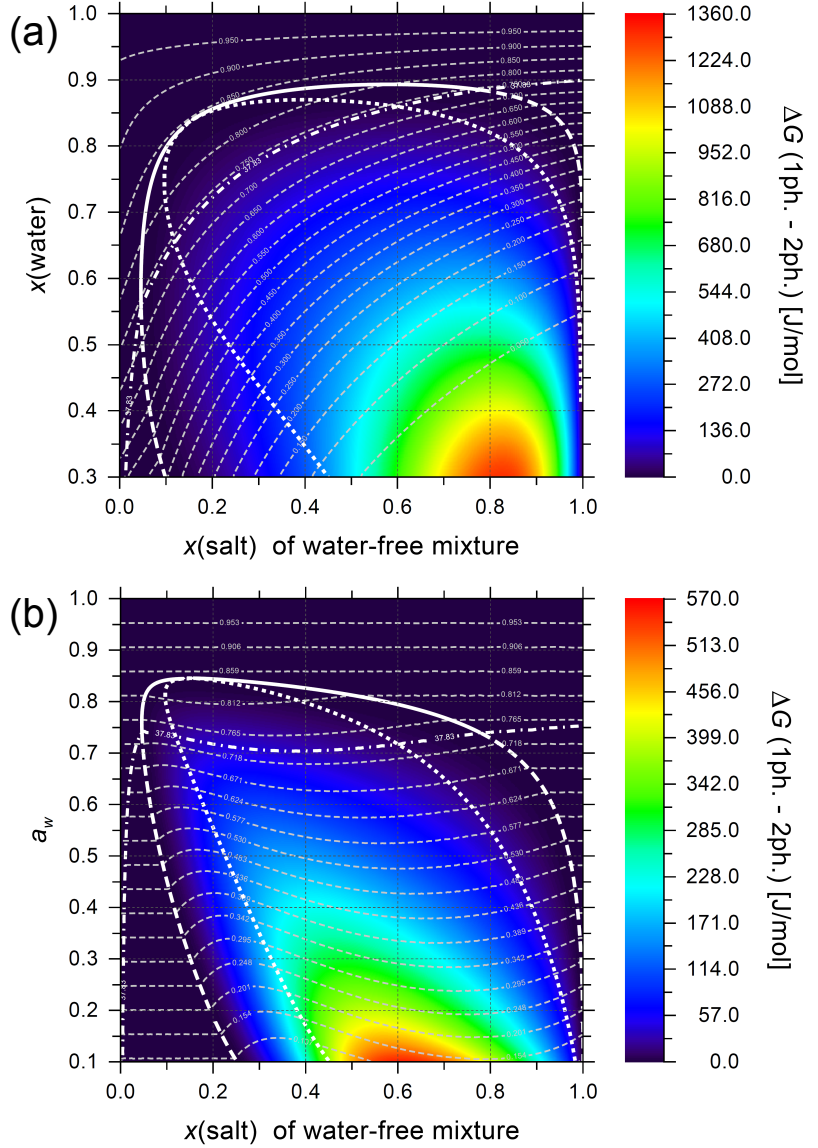

Fig. 3. Phase diagram depicting the Gibbs energy difference between a forced one-phase state and the predicted equilibrium state of the ternary 2-propanol-water- $\mathrm{NaCl}$ system at $298 \mathrm{~K}$. (a) Diagram in mole fraction coordinates, (b) as a function of water activity and water-free composition. The colour-axis indicates $\Delta G$ in $\mathrm{J} \mathrm{mol}^{-1}$ of mixture. White, solid and dashed curves are the coexistence curves (dashed part denotes supersaturation of $\mathrm{NaCl}$ ) and white, dotted the spinodals. The white, dashed-dotted line marks salt saturation. The thin, light grey, dashed lines are contour lines of constant equilibrium-state water activity. They represent tie-lines in the two-phase region.

the phase diagram, these contour lines of equilibrium- $a_{w}$ represent the water activity of the stable two-phase state at which a system will eventually end up at thermodynamic equilibrium. As these equilibrium-state activities are calculated at each point and as (in this framework) activities of coexisting phases are equal at equilibrium, these equilibrium-isoactivity lines furthermore connect the coexisting phases of a LLE. Therefore, within the miscibility gap, they represent tie-lines. Such tie-lines are defined by the feature of being "initialto-endpoint-lines" when plotted in different kinds of coordinate systems. Thus, tie-lines show for each initial one-phase composition the final compositions of the two phases in the equilibrium state, indicated by the intersection of the tie-line 

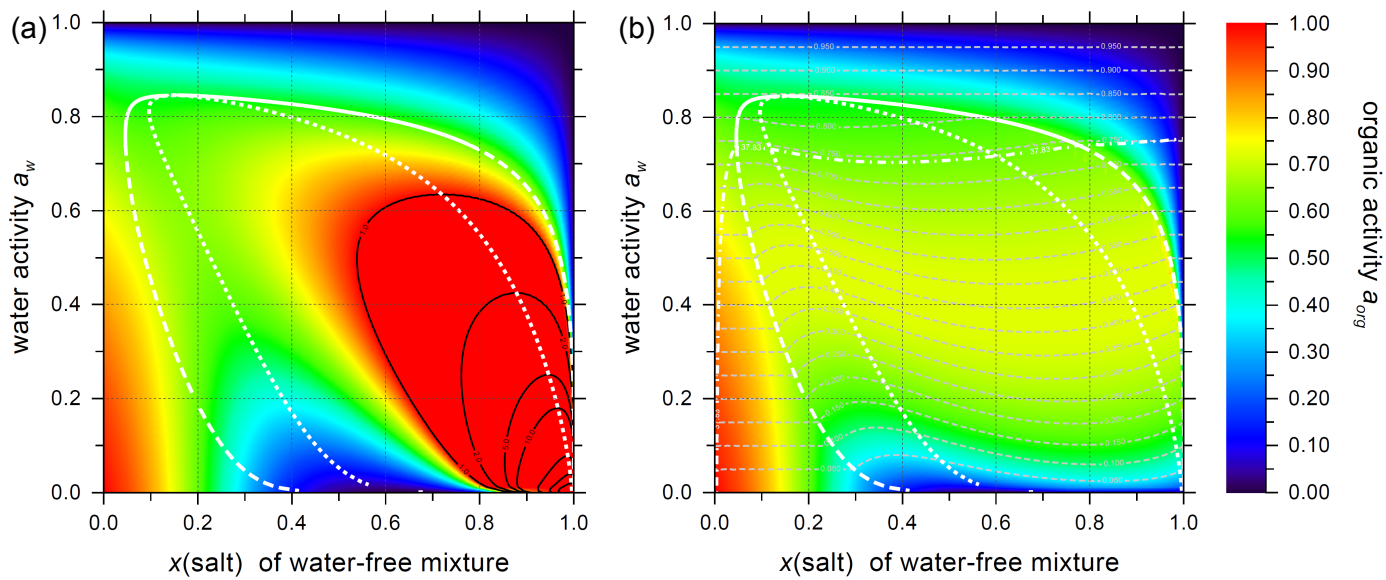

Fig. 4. Phase diagram showing organic activities of (a) forced one-phase state and (b) predicted equilibrium state of the ternary 2-propanolwater- $\mathrm{NaCl}$ system at $298 \mathrm{~K}$ as a function of water activity and water-free composition. The colour-axis represents the activity of 2-propanol in (a) the forced one-phase system and (b) the equilibrium system. Organic activities exceeding 1.0 are indicated by black contour lines in the red area. Binodal and spinodal curves are plotted for comparison and labelled as in Fig. 3. The thin, light grey, dashed lines are contour lines of constant equilibrium-state water activity (tie-lines in the two-phase region).

with the binodal curve. Note that for ternary LLE-systems, presented as ternary diagrams or on orthogonal coordinate systems with mass- or mole fractions on the coordinate axes (calculated on the same basis), tie-lines constitute straight lines connecting the two phases in equilibrium. However, tie-lines are curved when such systems are plotted on coordinate systems with mole fraction axes calculated on a different basis, e.g. $x$ (salt) on a water-free basis vs. $\mathrm{x}$ (water), as shown in Figs. 3, 4, and 6.

In a closed system, a liquid-liquid phase separation by the mechanism of spinodal decomposition will evolve along the corresponding tie-line until its intersection with the binodal. In the two-phase region, the equilibrium-isoactivity lines of all components are parallel curves to the tie-lines (by definition), as can be seen by comparison of the tie-lines with the molal ion activity product curve for the salt solubility limit in Fig. 3. Moreover, according to the Gibbs' phase rule for ternary systems at constant temperature and the characteristic monotonic behaviour of water activity over the entire composition space, the equilibrium system composition is fixed for a given water-free composition at a given $\mathrm{RH}\left(=a_{w}\right)$. All this information is graphically represented in panel (a) of Fig. 3. In the water activity representation of Fig. $3 \mathrm{~b}$ the water activity of the forced one-phase system is given on the y-axis, while the water activity of the equilibrium state is labelled on the tie-lines within the miscibility gap. The curvature of the tie-lines therefore demonstrates the change in water activity due to a liquid-liquid phase separation with respect to an initial one-phase state. This can be linked to a certain release/uptake of water by a liquid aerosol particle of such a mixture in equilibrium with virtually constant ambient RH.

Figure 4 shows the computed organic activity of the ternary system as a function of water-free mole fractions of
$\mathrm{NaCl}$ and water activity. In the forced one-phase system (Fig. 4a), the organic activity substantially exceeds that of a pure organic phase $\left(a_{\mathrm{org}}^{(x)}=1.0\right)$ at compositions of high salt mole fractions and lower water activities. This indicates the existence of a miscibility gap at equilibrium conditions. As can be seen from Panel (b), a phase separation is present well before $a_{\mathrm{org}}^{(x)}=1.0$ is reached. Thus, organic activities exceeding a value of 1.0 are not a necessary condition for the formation of LLE; rather, they point at composition areas where either a miscibility gap or the formation of a pure organic phase (i.e., externally mixed aerosol) is inevitable. The saddle point in the green area of Fig. $4 \mathrm{a}$ is a consequence of the salting-out effect of $\mathrm{NaCl}$ on 2-propanol. For an ideal ternary mixture, or in cases of rather weak organic-ion interactions, only the red area at low water activity and low salt content, indicating increasing organic activity with increasing organic content, exists, while the red area at higher salt mole fractions does not exist and for this reason also no saddle point. The blue area at low water activities, indicating low organic activity at high salt and low water contents, is caused by the steep increase of the ion activity product (highly supersaturated $\mathrm{NaCl}$ ) leading to a decrease in organic activity, consistent with Gibbs-Duhem relation for binary organic-salt solutions. Quantitative model predictions of one-phase state activities at compositions within the instability region, and for the stable/metastable areas far beyond salt saturation, are subject to potentially large inaccuracies due to extrapolation of the model parametrization and they are also hypothetical, as these areas reflect non-equilibrium states, not accessible for measurements. Approaching such compositions, either a liquid-liquid phase separation or crystallization of the salt will happen spontaneously, rendering experiments impossible. However, based on the composition range where 
experimental data have been available for the parametrization of the AIOMFAC model and the thermodynamic consistency of the model predictions, the one-phase activity predictions might be at least qualitatively correct in the experimentally inaccessible composition areas. The equilibriumstate organic activities plotted at overall mixture compositions within the miscibility gap, as shown in Fig. 4b, reflect the organic activities of the equilibrium state after phase separation (the values at the corresponding tie-line intersection with the binodal). The interactions of all mixture components restrict possible values of $a_{\mathrm{org}}^{(x)}$ to a certain range at a given water activity. This has direct implications on the behaviour of the ternary system when partitioning to the gas phase at ambient RH is considered.

Using the procedure described in Sect. 2.4.1, the liquidliquid coexistence curve of a system with a given particle phase composition can be calculated directly without recourse to a phase diagram that has to be established by a point-by-point computation. Nevertheless, the phase diagram together with the Gibbs energy and activities provide additional information. $\Delta G$ quantifies how unfavourable treating the system as a one-phase mixture would be. The activity plots indicate the change of chemical potential with respect to composition changes for each individual component. This information can only be gained from a model calculation.

\subsection{Computation of phase stabilities}

Real systems with a liquid-liquid miscibility gap typically show a hysteresis effect with respect to the actual phase separation process. This means that a metastable one-phase state may exist within the area bounded by the coexistence curve. Such a hysteresis behaviour can be explained by the existence of a free energy barrier, which has to be overcome for the formation of a (critical) stable second phase. This mechanism of phase separation, classified by Gibbs as discontinuous phase change (Gibbs, 1928), is also known as nucleation-and-growth described by the classical nucleation theory - analogously to the formation of a solid state in a supersaturated liquid (e.g., the efflorescence of a salt).

Both theory and experiment show that there exists a limit of stability/metastability of liquid multicomponent onephase solutions with respect to continuous phase changes leading to separation into two phases (Gibbs, 1928; Cahn, 1965). This limit marks the boundary of stability or metastability to the area of instability of a corresponding one-phase state. The points (curves, surfaces,..., depending on the system's degrees of freedom) at the instability limit are called spinodal. Common points of a binodal and a spinodal are known as plait points - or critical points in the temperaturepressure diagram representation. Panel (c) of Fig. 1 shows a schematic phase diagram of a liquid-liquid miscibility gap in a three-component mixture. The metastable composition area, bounded by the binodal and spinodal curves, vanishes at the plait point, the only stable point on the spinodal curve.

A hypothetical liquid one-phase mixture within the unstable area will spontaneously separate into two phases upon infinitesimal system fluctuations (e.g., composition or density fluctuations). In this case, the free energy barrier for phase separation vanishes below the thermal energy of the molecules (Debenedetti, 1996; Filobelo et al., 2005). Hence, there is no barrier other than a diffusional one to impede this process. This phase separation mechanism is known as spinodal decomposition. It can be described by a transport process of "uphill diffusion" with a negative mutual diffusion coefficient (Saxena and Caneba, 2002). During the process of phase separation, spinodal decomposition manifests in the optical signature of so called "schlieren" (e.g., Ciobanu et al., 2009). Using a Legendre transform to obtain pressure, temperature and number of moles of components as the set of independent thermodynamic variables, i.e., $G\left(p, T, n_{1}, n_{2}, \ldots, n_{k}\right)$, the criterion for the spinodal can be expressed in terms of 2nd derivatives of Gibbs energy (Modell and Reid, 1983). For a ternary system, the corresponding determinant $L$ is calculated by (Modell and Reid, 1983; Debenedetti, 1996):

$L=\left|\begin{array}{ll}\left(\frac{\partial^{2} G}{\partial n_{1}^{2}}\right)_{p, T, n_{2}, n_{3}} & \left(\frac{\partial^{2} G}{\partial n_{1} \partial n_{2}}\right)_{p, T, n_{3}} \\ \left(\frac{\partial^{2} G}{\partial n_{1} \partial n_{2}}\right)_{p, T, n_{3}} & \left(\frac{\partial^{2} G}{\partial n_{2}^{2}}\right)_{p, T, n_{1}, n_{3}}\end{array}\right|$

or in terms of the chemical potentials:

$L=\left|\begin{array}{ll}\left(\frac{\partial \mu_{1}}{\partial n_{1}}\right)_{p, T, n_{2}, n_{3}} & \left(\frac{\partial \mu_{1}}{\partial n_{2}}\right)_{p, T, n_{1}, n_{3}} \\ \left(\frac{\partial \mu_{1}}{\partial n_{2}}\right)_{p, T, n_{1}, n_{3}} & \left(\frac{\partial \mu_{2}}{\partial n_{2}}\right)_{p, T, n_{1}, n_{3}}\end{array}\right|$.

Hence,

$$
\begin{aligned}
L=\left(\frac{\partial \mu_{1}}{\partial n_{1}}\right)_{p, T, n_{2}, n_{3}} \times\left(\frac{\partial \mu_{2}}{\partial n_{2}}\right)_{p, T, n_{1}, n_{3}} & -\left[\left(\frac{\partial \mu_{1}}{\partial n_{2}}\right)_{p, T, n_{1}, n_{3}}\right]^{2} .
\end{aligned}
$$

The spinodal as the limit of stability/metastability is defined by the points where the condition $L=0$ is fulfilled. Thus, points on the spinodal curve are inflection points on the Gibbs energy curve of the (forced) one-phase solution.

In contrast to computing the binodal, the spinodal curve can be calculated directly from an expression for the Gibbs energy or the chemical potentials of the (one-phase) system without a computationally expensive Gibbs energy minimization. We use a 2-D scan procedure similar to the one described for the binodal in Sect. 2.4.1 to search the composition space for the roots of $L$. The Differential Evolution algorithm is used to minimize $L^{2}$ as a function of $x$ (water) 
at fixed $x$ (salt, w-f). Then a check is applied to ensure that the minimum found is indeed a root of $L$. The possibility of more than one root at a given $x$ (salt, w- $\mathrm{f}$ ) coordinate is also accounted for. The determinant $L$ is calculated from Eq. (20) using numerical solutions for the partial derivatives of the chemical potentials by means of central differences. As the 2-D scan is performed in mole fraction composition space, central differences with respect to differences of moles of a certain compound can be easily converted to variations in mole fractions (affecting all compounds) by arbitrarily assuming a total molar amount of, e.g., $1 \mathrm{~mol}$ mixture before the variation.

Predicted spinodals for the ternary 2-propanol-water- $\mathrm{NaCl}$ mixture are plotted as dotted curves in Figs. 2, 3 and 4. Figure 5 illustrates the stability, metastability, and instability areas in terms of a point-by-point computation of the determinant $L$. To discriminate between metastable and stable one-phase areas, the coexistence curve is plotted as well. The scaling of the colour-axis is arbitrarily chosen and centred at $L=0$ to show the spinodal in white. Values of the determinant $L$ outside the range of the shown colour-axis are coloured by the maximum and minimum values, respectively. The whole blue area is unstable - no matter what shade of blue. Albeit the arbitrary colour scale, different shades of red in the metastable region can be interpreted as a qualitative indicator for a preferred phase separation mechanism upon local composition fluctuations, i.e., the transition from nucleation-and-growth to spinodal decomposition.

The computation of spinodal curves and the stability diagram are useful to complement and interpret laboratory experiments. Unstable regions in the phase diagram are virtually inaccessible for experimental techniques as a phase separation will occur spontaneously in this region. Measurements of the spinodal curve are a difficult task as the metastable region has to be crossed. For gas/particle partitioning calculations, it is typically not necessary to compute the spinodal curves. For offline computations of well defined multicomponent mixtures, however, the spinodal indicates those regions in composition space, where no one-phase solution can exist. It is therefore a measure for the composition range (the metastable region) where hysteresis effects with respect to liquid-liquid phase separations might play a role.

\subsection{Further ternary alcohol/polyol-water-salt phase diagrams}

To demonstrate the described methods, we compute a number of phase diagrams of ternary alcohol/-polyol-water-salt mixtures at room temperature. These examples include mixtures that were used to fit AIOMFAC interaction coefficients as well as mixtures for which no experimental data are available to compare with. We also make use of the groupcontribution based predictive capability of AIOMFAC to calculate phase diagrams of multifunctional polyol-water-salt mixtures. The selection of systems in this section includes

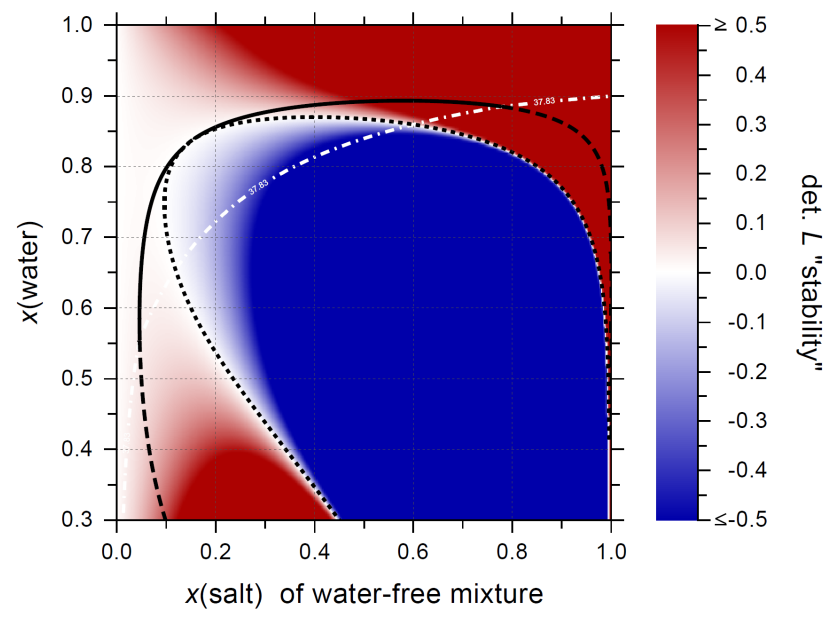

Fig. 5. Phase stability diagram with respect to a one-phase state of the ternary 2-propanol-water- $\mathrm{NaCl}$ system at $298 \mathrm{~K}$. Values of the determinant $L$ are shown on the colour-axis. White $L=0$ values indicate the spinodal, also drawn as black dotted curve. Shades of red indicate the stable or metastable one-phase area, shades of blue indicate the unstable region. Binodal (black solid and dashed) and spinodal (black, dotted) curves border the metastable region. The white, dashed-dotted line marks salt saturation.

all ternary polyol-water-salt mixtures out of the multicomponent mixture described in Sect. 3.

Figure 6 shows the computed phase and stability diagrams in composition coordinates with corresponding equilibrium water activities plotted as contour lines. The mixtures presented in panels (a) $\mathrm{H}_{2} \mathrm{O}+1$-butanol $+\mathrm{NaCl}$, (b) $\mathrm{H}_{2} \mathrm{O}+$ tertbutanol+ $+\mathrm{Na}_{2} \mathrm{SO}_{4}$, and (d) $\mathrm{H}_{2} \mathrm{O}+1$, 6-hexanediol $+\left(\mathrm{NH}_{4}\right)_{2} \mathrm{SO}_{4}$ have phase separations in a certain composition range of the salt-free, binary alcohol-water solution. The more polar and hydrophilic an alcohol/polyol is, the smaller the miscibility gap. With its three hydroxyl groups and an $\mathrm{O}: \mathrm{C}$ atomic ratio of 1:1, glycerol is a good example of a highly hydrophilic polyol. The $\mathrm{H}_{2} \mathrm{O}+$ glycerol+ $\left(\mathrm{NH}_{4}\right)_{2} \mathrm{SO}_{4}$ system shows a phase separation only at compositions where ammonium sulphate is already supersaturated with respect to its solid phase (Fig. 6c). For this specific ternary mixture two distinct LLE areas are also predicted. Similar ternary systems with different salts: $\mathrm{H}_{2} \mathrm{O}+$ glycerol $+\mathrm{NaCl}, \mathrm{H}_{2} \mathrm{O}+$ glycerol $+\mathrm{Na}_{2} \mathrm{SO}_{4}$, $\mathrm{H}_{2} \mathrm{O}+$ glycerol $+\mathrm{NH}_{4} \mathrm{NO}_{3}$, and $\mathrm{H}_{2} \mathrm{O}+$ glycerol $+\mathrm{NH}_{4} \mathrm{Cl}$ show only one binodal curve, although the $\mathrm{H}_{2} \mathrm{O}+$ glycerol $+\mathrm{Na}_{2} \mathrm{SO}_{4}$ system shows two partially different spinodal curves that merge in the same miscibility gap. Given this information, the second miscibility gap of the $\mathrm{H}_{2} \mathrm{O}+$ glycerol $+\left(\mathrm{NH}_{4}\right)_{2} \mathrm{SO}_{4}$ system is likely caused by - $\mathrm{OH}$ group $-\mathrm{SO}_{4}^{2-}$ interactions, but whether this is a model parametrization artefact or a real feature is unclear.

At a salt mole fraction of 0.4 in the water-free mixture, the water activities of the LLE onsets (binodal) for the systems of Fig. 6 are: (a) 0.96, (b) 0.94, (c) 0.74, (d) 0.97, (e) 0.96, and (f) 0.98 . Thus, with the exception of the glycerol mixture, 

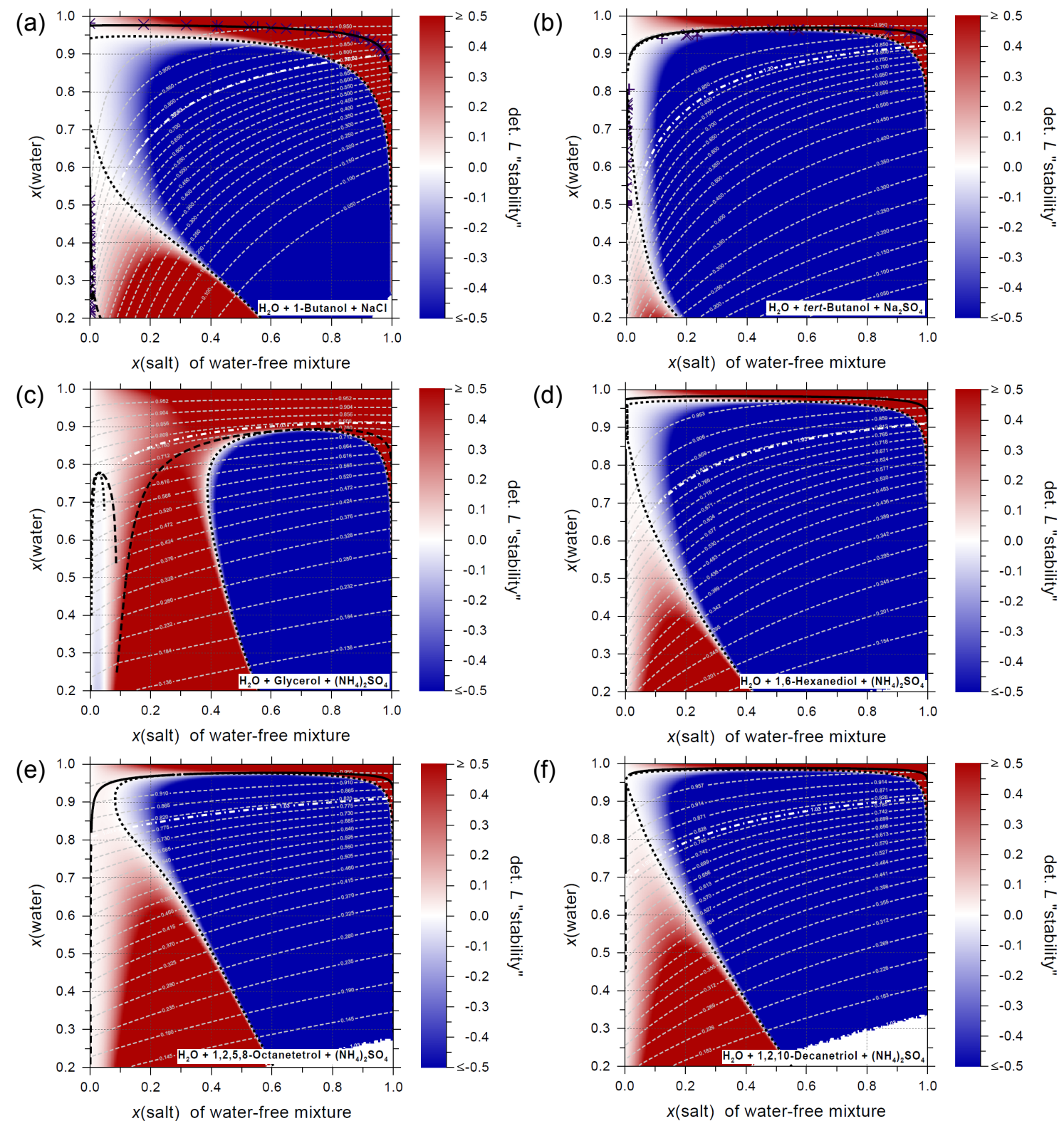

Fig. 6. Phase diagrams of ternary alcohol/polyol-water-salt mixtures at $298 \mathrm{~K}$. Black, solid and dashed curves are the binodal curves (dashed part denotes supersaturation of salt) and black, dotted curves the spinodals. The white, dashed-dotted line marks salt saturation. The thin, light grey, dashed lines are contour lines of constant equilibrium-state water activity (tie-lines in the two-phase region). The stability of a one-phase solution is shown on the colour-axis. Experimental LLE phase composition: in (a) by De Santis et al. (1976), ( $\times$ ) and Li et al. (1995), (+); in (b) by Lynn et al. (1996), (×) at $308 \mathrm{~K}$ and Brenner et al. (1992), (+) at 296-353 K.

the model predicts phase separations at water activities as high as 0.95 . Comparing these values with the typical tropospheric RH range, being often below $90 \%$ RH (e.g., Gaffen et al., 1992; Pierrehumbert et al., 2007), such mixtures would frequently exhibit liquid-liquid equilibria.

\section{Gas/particle partitioning}

\subsection{General partitioning theory}

We consider a thermodynamic system consisting of a gas phase $(g)$ and liquid or solid particulate matter phases, in which volatile and semivolatile compounds partition. One of the most prominent volatile species in the atmospheric aerosol is, of course, water, being present in the forms of 
water vapour and as liquid water or ice in aerosol particles. VLE and VLLE are equilibrium states established as a result of molecular gas/particle (vapour/liquid) partitioning. In this study, we focus on gas/particle partitioning involving liquid aqueous particles (gas/liquid partitioning). The gas/particle partitioning of each system component at thermodynamic equilibrium depends on a number of factors: temperature, total pressure, system volume, total amounts of the different chemical components in the system, pure component vapour pressures, and interactions in the gas and liquid phases (nonideality). Regarding atmospheric aerosols, the basic problem is: Given the total amounts (moles or masses) of different chemical species in a defined volume of air (e.g., $\left.1 \mathrm{~m}^{3}\right)$ at known ambient conditions (pressure, temperature, and $\mathrm{RH}$ ), how do the different species partition between the PM (solid, liquid phases) and the gas phase? How many phases and of what compositions coexist at equilibrium?

A commonly used form to express the gas/particle partitioning of different semivolatile compounds in terms of their concentrations in both phases is (Yamasaki et al., 1982; Pankow, 1994, 2003; Odum et al., 1996; Bowman and Melton, 2004):

$K_{j}^{\mathrm{PM}}=\frac{F_{j} / \mathrm{TPM}}{A_{j}}=\frac{R T f}{10^{6} M_{o m} \gamma_{j}^{(x)} p_{j}^{\circ}}$,

where $K_{j}^{\mathrm{PM}}$ is the particle/gas equilibrium "constant" $\left(\mathrm{m}^{3} \mu \mathrm{g}^{-1}\right), F_{j}$ is the PM phase concentration of $j\left(\mathrm{ng} \mathrm{m}^{-3}\right)$, TPM the total suspended PM mass $\left(\mu \mathrm{g} \mathrm{m}^{-3}\right), A_{j}$ the gas phase concentration $\left(\mathrm{ng} \mathrm{m}^{-3}\right), R\left(\mathrm{~J} \mathrm{~K}^{-1} \mathrm{~mol}^{-1}\right)$ is the universal gas constant, $f$ the mass fraction of the absorbing phase in the TPM, and $M_{o m}\left(\mathrm{~g} \mathrm{~mol}^{-1}\right)$ the average molar mass of the absorbing organic (PM) phase. Assuming that the PM phase is a liquid mixture (an absorbing organic-inorganic solution), that the gas phase is an ideal gas mixture, using SI units and expressing Eq. (21) in terms of moles instead of mass, the molar (superscript $(n)$ ) particle/gas equilibrium coefficient $K_{j}^{\mathrm{PM},(n)}$ is:

$$
K_{j}^{\mathrm{PM},(n)}=\frac{x_{j}^{\mathrm{PM}}}{p_{j}} R T=\frac{R T}{\gamma_{j}^{(x)} p_{j}^{\circ}} .
$$

Pure compound saturation vapour pressures are a function only of temperature; thus, with the given assumptions, $K_{j}^{\mathrm{PM},(n)}$ is a function of temperature and the mixture nonideality in terms of activity coefficients. For an ideal solution $\left(\gamma_{j}^{(x)}=1\right), K_{j}^{\mathrm{PM},(n)}$ is just a function of temperature and therefore an intrinsic property of component $j$. Donahue et al. (2006) introduced a modified version of Eq. (21) for the partitioning of organic aerosols by replacing $K_{j}^{\mathrm{PM}}$ with its (slightly modified) inverse, called the effective saturation concentration $C_{j}^{*, \mathrm{OA}}\left(\mu \mathrm{g} \mathrm{m}^{-3}\right)$ :

$C_{j}^{*, \mathrm{OA}}=\frac{C_{j}^{g} C_{\mathrm{OA}}}{C_{j}^{\mathrm{PM}}}$.
Here $C_{j}^{g}\left(\mu \mathrm{g} \mathrm{m}^{-3}\right)$ is the mass concentration of compound $j$ in the gas phase, $C_{j}^{\mathrm{PM}}\left(\mu \mathrm{g} \mathrm{m}^{-3}\right)$ is its concentration in the condensed phase ( $\mu \mathrm{g}$ of $j$ in the PM per $\mathrm{m}^{3}$ of air), and $C_{\mathrm{OA}}\left(\mu \mathrm{g} \mathrm{m}^{-3}\right)$ the total organic aerosol particle concentration. $C_{\mathrm{OA}}$ can be considered a normalisation term to reduce the variability of $C_{j}^{*, \mathrm{OA}}$ with respect to dilution effects. The ratio of $C_{j}^{\mathrm{PM}} / C_{\mathrm{OA}}$ reduces the partitioning sensitivity of compound $j$ with respect to changes in total organic aerosol, as an increase of other organic material in the PM (enhancing $C_{\mathrm{OA}}$ ), will reduce the PM concentration of $j$ and therefore force partitioning of compound $j$ into the PM to maintain equilibrium. Equation (23) mainly aims at describing the gas/particle partitioning of semivolatile organics in the absence of inorganic electrolyte components. We modify slightly this gas/particle partitioning expression to include dissolved inorganics in the absorbing phase by generalizing Eq. (23) to

$C_{j}^{*}=\frac{C_{j}^{g} \sum_{k} C_{k}^{\mathrm{PM}}}{C_{j}^{\mathrm{PM}}}$,

where the sum goes over all species in the liquid mixture. Although organic compounds will tend to preferentially partition to the organic-rich phase in case of a phase separation, absorption into the aqueous electrolyte phase is an option as well, since the activity of an absorbed molecule is the same in both phases (at equilibrium conditions). Upon further absorption, LLE phase compositions adjust to keep the phases in equilibrium. It is therefore justified to consider the total liquid mixture as the absorbing phase. However, in case of a phase separation, the organic-rich phase is typically the outer phase enclosing the electrolyte-rich phase, so that absorption takes place directly to the organic phase (Ciobanu et al., 2009). If no inorganics are present, or the water content of a primarily (hydrophobic) organic aerosol particle is negligible, Eq. (24) reduces to Eq. (23).

\subsection{Calculating gas/particle partitioning}

Our approach to calculate gas/particle partitioning in the presence of multiple condensed phases follows for the most part the framework of Pankow (2003). However, we prefer the use of molar amounts and mole fractions instead of compound masses. Figure 7 outlines the modules of the gas/particle partitioning model. Basically, two interconnected boxes describe the gas phase and the PM phase in terms of number of moles of the different chemical components at given temperature and RH. If a liquid-liquid equilibrium is the stable PM state, the phase is further divided into two coexisting phases. In such cases, compositions and sizes of PM phases $\alpha$ and $\beta$ are calculated using the LLE algorithm described in Sect. 2.4. The gas phase is treated as an ideal gas mixture of given volume $V^{g}$ (typically: $V^{g}=1 \mathrm{~m}^{3}$ ). For systems at atmospheric pressures, this is a common and 


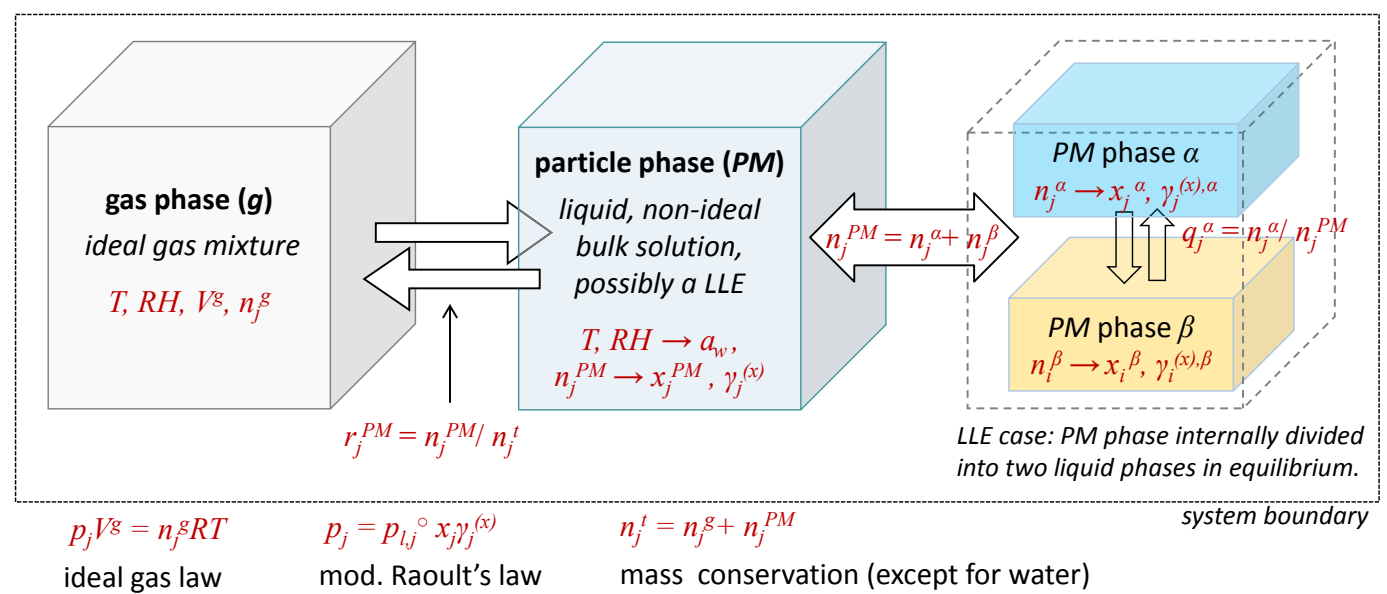

Fig. 7. Schematic representation of the gas/particle partitioning model. For the cases in which a liquid-liquid phase separation is predicted, the particulate matter phase is divided into two coexisting phases of different sizes and compositions. All system components are coupled through PM phase non-ideality.

justifiable simplification (Seinfeld and Pandis, 1998), leaving all non-ideality effects to the particle phase. The PM is treated as a liquid bulk mixture in which non-ideality is considered in terms of activity coefficients, here calculated using AIOMFAC. PM phase non-ideality, the potential for phase separations, and the interconnection between the different phases make this system highly nonlinear and fully coupled. That is, if the molar amount of one species in one of the phases changes, there is an impact on every other species and on all other phases. Thus, to compute the equilibrium system, an iterative procedure is necessary. Given the total system amount of the chemical components, $n_{j, j \neq w}^{t}, T$, and $\mathrm{RH}$, each iteration loop consists of the following steps:

(1) $r_{j}^{\mathrm{PM}}=\frac{n_{j}^{\mathrm{PM}}}{n_{j}^{t}}$ : set vector of all components (except water) gas/particle partitioning ratios to calculate $n_{j}^{\mathrm{PM}}$. For water, $x_{w}^{\mathrm{PM}}$ is set and $n_{w}^{\mathrm{PM}}$ is calculated from $x_{w}^{\mathrm{PM}}$ and $n_{j}^{\mathrm{PM}}$ of all other species.

(2) $x_{j}^{\mathrm{PM}}=\frac{n_{j}^{\mathrm{PM}}}{\sum_{j^{\prime}} n_{j^{\prime}}^{\mathrm{PM}}}$ : calculate PM mole fractions of all $(j=$ $1, \ldots, k)$ components.

(3) $\gamma_{j}^{(x)}=\operatorname{AIOMFAC}\left(T, x_{1}^{\mathrm{PM}}, x_{2}^{\mathrm{PM}}, \ldots, x_{k}^{\mathrm{PM}}\right)$ : use AIOMFAC model to calculate activity coefficients at current composition.

(4) Use Gibbs energy minimization algorithm with AIOMFAC to check for LLE. If phase separation occurs, calculate compositions of phases $\alpha$ and $\beta$ and the corresponding activity coefficients.

(5) $a_{j}^{(x)}=x_{j}^{\mathrm{PM}} \gamma_{j}^{(x)}$ or $a_{j}^{(x)}=x_{j}^{\alpha} \gamma_{j}^{(x), \alpha}, a_{j}^{(x)}=x_{j}^{\beta} \gamma_{j}^{(x), \beta}$ : AIOMFAC activities in the solution.

(6) $p_{j}=p_{j}^{\circ} a_{j}^{(x)}$ : use modified Raoult's law to calculate corresponding partial pressures.
(7) $n_{j}^{g}=p_{j} \frac{V^{g}}{R T}$ : use ideal gas law for mixtures to calculate gas-phase molar amounts in equilibrium with the liquid mixture.

(8) $\Delta n_{j}=n_{j}^{t}-\left(n_{j}^{\mathrm{PM}}+n_{j}^{g}\right)$ : deviations $\Delta n_{j}$ of the calculated total amounts $\left(n_{j}^{\mathrm{PM}}+n_{j}^{g}\right)$ from the given total amounts $n_{j}^{t}$ of all components except for water, where $\Delta a_{w}=a_{w}^{(x)}-\mathrm{RH}$ is calculated.

This iteration procedure is repeated until a closure between steps (1) and (8) is found, i.e., all $\Delta n_{j, j \neq w}=0$ and $\Delta a_{w}=0$. Similarly to the LLE computation, we use a combination of the Differential Evolution method to minimize the objective function $F_{\mathrm{obj}}=\sum_{j, j \neq w} \Delta n_{j}{ }^{2}+\Delta a_{w}{ }^{2}$ and - to advance convergence to the root - the Levenberg-Marquardt algorithm by solving the system of equations in step (8) as a function of the set of $r_{j}^{\mathrm{PM}}$ partitioning ratios. The Gibbs minimization check for the potential existence of a LLE requires an additional, computationally expensive iteration in the loop of the gas/particle partitioning iteration procedure. Therefore, a sophisticated optimization algorithm is crucial. To reduce the number of gas/particle partitioning iterations, we calculate the system at first for an ideal liquid mixture. The $r_{j}^{\mathrm{PM}}$ values determining the ideal mixture are then introduced as an initial guess for the subsequent computation of a forced one-phase PM mixture. The combined information from the ideal and the one-phase solutions are then used as initial $r_{j}^{\mathrm{PM}}$ values and to estimate the range of possible $r_{j}^{\mathrm{PM}}$ values for the equilibrium PM mixture calculations. Note that the thermodynamic system is only semi-closed, as the ambient RH is fixed, not the total amount of water. As a consequence of this, a normalized molar Gibbs energy (Eq. 16), e.g., for 1 mol mixture, has to be used to determine the PM state in the LLE computation, rather than using the extensive expression 
of Gibbs energy (Eq. 15), which depends on the total amount of water.

The partial pressure calculation using modified Raoult's law in step (6) requires knowledge of the pure liquid compound vapour pressures $p_{j}^{\circ}$ at $T$. For common volatile compounds, parametrizations such as the Antoine equation can be used to quite accurately describe $p_{j}^{\circ}$ at atmospheric temperatures. However, for many semivolatile, multifunctional species, no vapour pressure measurements or Antoine coefficients are available. Therefore, vapour pressure estimation methods based on molecular structures and boiling point temperatures (if available) are often the only way to obtain $p_{j}^{\circ}$ for such semivolatile compounds. This constitutes one of the major sources of uncertainty in gas/particle partitioning computations (Camredon and Aumont, 2006; Clegg et al., 2008; Hallquist et al., 2009; Barley and McFiggans, 2010).

Besides the described gas/particle partitioning mode (i) with given $T, \mathrm{RH}$, and $n_{j, j \neq w}^{t}$, we implement also two other modes to calculate the gas/particle partitioning: (ii) given $T$, $\mathrm{RH}$, and water-free PM composition in terms of $n_{j, j \neq w}^{\mathrm{PM}}$, and (iii) given $T$ and $n_{j}^{t}$ (including water), leaving RH as a variable of the closed system. For atmospheric aerosol applications, modes (i) and (ii) are more relevant.

\section{Gas/particle partitioning of a six-component mixture}

\subsection{System definition}

The computation of gas/particle partitioning is applied to a six-component organic-inorganic mixture at room temperature. The six components are water, glycerol, 1,6-hexanediol, 1,2,5,8-octanetetrol, 1,2,10-decanetriol, and $\left(\mathrm{NH}_{4}\right)_{2} \mathrm{SO}_{4}$. This system of water, ammonium sulphate, and four polyols is chosen because AIOMFAC is able to explicitly treat organic-inorganic interactions of alcohols/polyols with ammonium sulphate; other functional group-salt interactions are the subject of ongoing work with AIOMFAC. Furthermore, the polyols represent compounds of different degrees of hydrophilicity (water solubility), as well as different saturation vapour pressures, covering a range of $C_{j}^{*}$ values attributed to organic compounds of lower and intermediate volatility. This simulation aims at demonstrating the general effects on gas/particle partitioning of semivolatile organic compounds, which is of importance for understanding the behaviour of aerosol systems more related to actual atmospheric cases.

Table 1 lists a selection of physical properties of the six compounds. While the pure compound vapour pressures of water, glycerol, and 1,6-hexanediol are based on measurements and therefore assumed accurate, no measurements are available for 1,2,5,8-octanetetrol and 1,2,10decanetriol. For this reason, we use the molecular structurebased vapour pressure estimation methods accessible at the Extended AIM Aerosol Thermodynamics Model (E-AIM) website (Clegg et al., 2008) (http://www.aim.env.uea.ac.uk/ aim/aim.php). That is: boiling point estimation by Nannoolal et al. (2004) and $p_{j}^{\circ}$ estimation method of Moller et al. (2008) (method 1).

A semi-closed system of six components at constant temperature and gas-phase volume is 6-dimensional, with five degrees of freedom regarding mixture compositions. According to Eq. (22), the equilibrium partitioning varies with composition. In this example we will not discuss effects of all possible configurations in composition; rather, we have chosen a system of constant water-free total composition (mode i). We set the total molar amounts of each of the four organics in a volume $V^{g}=1 \mathrm{~m}^{3}$ to $n_{\mathrm{org}}^{t}=3.0 \times$ $10^{-8} \mathrm{~mol}(30 \mathrm{nmol})$ and the amount of ammonium sulphate to $n_{\left(\mathrm{NH}_{4}\right)_{2} \mathrm{SO}_{4}}^{t}=1.0 \times 10^{-8} \mathrm{~mol}$. This overall system composition produces PM mass concentrations comparable to ambient measurements in minor to moderately polluted air. A mixture of six components could, in principle, lead to more than two liquid phases at equilibrium, but, from the point of view of practicality, an aqueous electrolyte phase and an (aqueous) organic phase are assumed to be the most prevalent liquid phases for multiphase atmospheric aerosols. Therefore, following Chang and Pankow (2006), we call the model calculations in which two liquid phases are allowed to coexist the equilibrium (equil.) case and in which only a single liquid phase containing all PM components is considered, the one-phase (1-ph.) case. Note also that in both cases the formation of solid inorganic or organic phases is not considered in order to allow supersaturated conditions.

By varying RH in the range of $20 \%$ to $99 \%$, effects on the gas/particle partitioning of the organics are calculated. Additionally, the implications of liquid-liquid phase separation in comparison with a forced one-phase solution are studied.

\subsection{RH-dependent phase compositions}

Figure 8 shows the computed (water-free) mole fraction composition of the gas phase and corresponding compositions (including water) of the PM phases $\alpha$ and $\beta$ over the RH range considered. The resolution of the computation is $2 \%$ $\mathrm{RH}$, with the exception of the prediction at $99 \% \mathrm{RH}$. Starting at the highest RH, the onset of liquid-liquid phase equilibrium occurs at a $\mathrm{RH}$ between $98 \%$ and $96 \%$. At $98 \% \mathrm{RH}$ and above, the compositions of phases $\alpha$ and $\beta$ are identi$\mathrm{cal}$, meaning that there exists no phase separation, and the discrimination into the two phases in the graphical representation is artificial. In comparison, the corresponding salt-free five-component system does not show liquid-liquid phase separation at all. Hence, the strong ion-organic functional group interactions (salting-out effect) are responsible for the liquid-liquid phase separation. At $90 \% \mathrm{RH}$, the phase separation is already quite complete with less than $0.5 \%$ of the organic mass remaining in the aqueous-electrolyte phase, while still around $2 \%$ of the $\left(\mathrm{NH}_{4}\right)_{2} \mathrm{SO}_{4}$ mass is found in the organic-rich phase, as phase $\beta$ has still a high water content 
Table 1. Pure compound physical properties of the six components used in the gas/particle partitioning example.

\begin{tabular}{llrrrr}
\hline compound & chemical formula & $M\left(\mathrm{~kg} \mathrm{~mol}^{-1}\right)$ & $p^{\circ}(298 \mathrm{~K})(\mathrm{Pa})^{\mathrm{a}}$ & $T_{b}(\mathrm{~K})^{\mathrm{b}}$ & O:C ratio \\
\hline water & $\mathrm{H}_{2} \mathrm{O}$ & $1.80153 \mathrm{E}-02$ & 3168.49 & 373 & - \\
glycerol & $\mathrm{C}_{3} \mathrm{H}_{5}(\mathrm{OH})_{3}$ & $9.20940 \mathrm{E}-02$ & $2.284 \mathrm{E}-02$ & 588 & 1.0 \\
1,6 -hexanediol & $\mathrm{C}_{6} \mathrm{H}_{12}(\mathrm{OH})_{2}$ & $1.18172 \mathrm{E}-01$ & $5.695 \mathrm{E}-02$ & 525 & 0.33333 \\
$1,2,5,8-$ octanetetrol & $\mathrm{C}_{8} \mathrm{H}_{14}(\mathrm{OH})_{4}$ & $1.78224 \mathrm{E}-01$ & $6.725 \mathrm{E}-05$ & 640 & 0.5 \\
1,2,10-decanetriol & $\mathrm{C}_{10} \mathrm{H}_{19}(\mathrm{OH})_{3}$ & $1.90276 \mathrm{E}-01$ & $1.826 \mathrm{E}-04$ & 622 & 0.3 \\
ammonium sulphate & $\left(\mathrm{NH}_{4}\right)_{2} \mathrm{SO}_{4}$ & $1.32139 \mathrm{E}-01$ & $(0.0)$ & - & - \\
\hline
\end{tabular}

${ }^{a} p^{\circ}(298 \mathrm{~K})$ data references: water and glycerol using Antoine equation with parameters from Dykyj et al. (2000); 1,6-hexanediol calculated from VonNiederhausern et al. (2006) using extrapolation to subcooled liquid vapour pressure with the given Riedel parametrization; 1,2,5,8-octanetetrol and 1,2,10-decanetriol calculated using the vapour pressure estimators from Extended AIM Aerosol Thermodynamics Model (E-AIM) website (Clegg et al., 2008) (http://www.aim.env.uea.ac.uk/aim/aim.php) by method 1: boiling point by Nannoolal et al. (2004) and $p^{\circ}$ estimation method of Moller et al. (2008). Number of digits does not represent accuracy of measurement/estimation.

${ }^{\mathrm{b}} T_{b}(101325 \mathrm{~Pa})$ data references: water and glycerol from Speight (2005); 1,6-hexanediol from VonNiederhausern et al. (2006); 1,2,5,8-octanetetrol and 1,2,10-decanetriol as in a (Nannoolal et al., 2004).

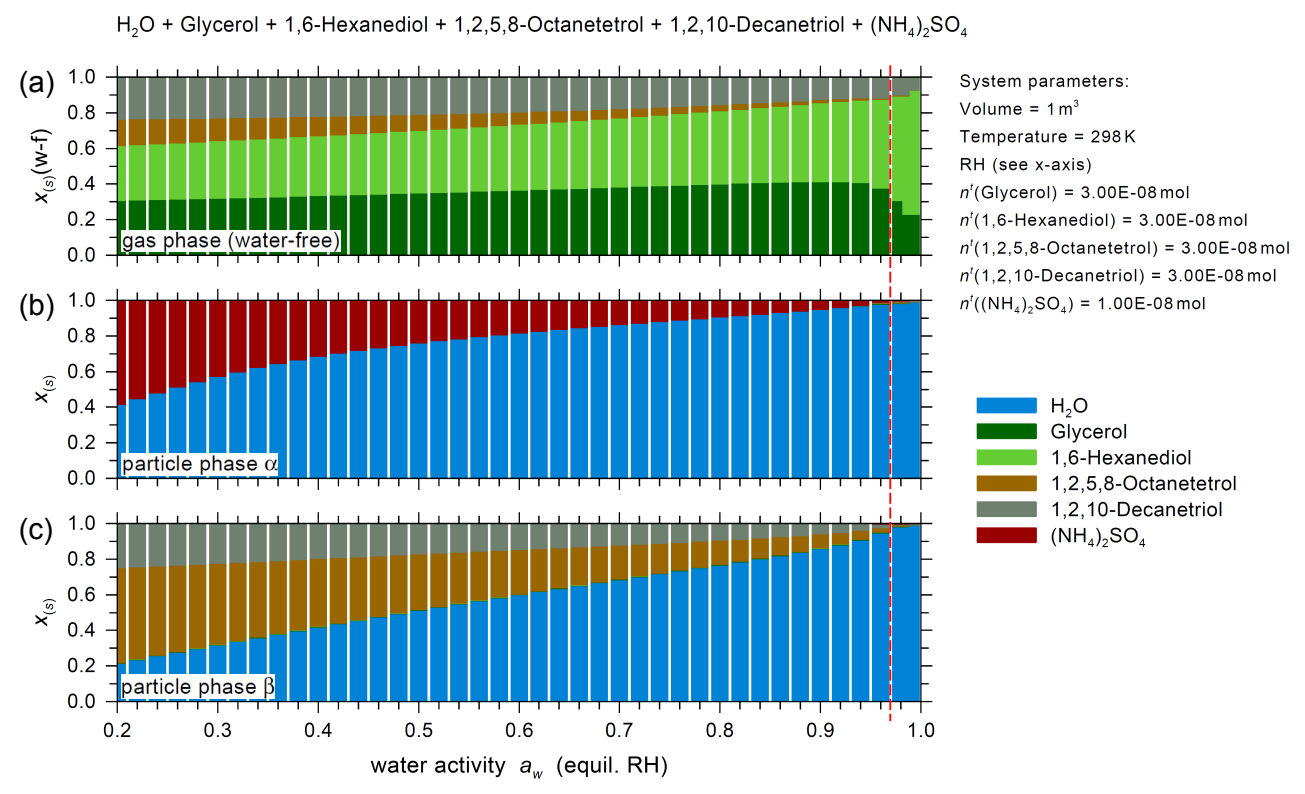

Fig. 8. Composition diagrams of the coexisting phases at RH ranging from $20 \%$ to $99 \%$. (a) Mole fractions calculated with respect to the water-free gas phase composition. Panels (b) and (c) show the mole fractions calculated with respect to undissociated salt for the two PM phases. At RH above $96 \%$, marked by the red, dashed line, a one-phase liquid particle is the equilibrium state, while at $96 \%$ and below, the differing compositions of phases $\alpha$ and $\beta$ indicate LLE.

and is about twice the size of phase $\alpha$ at this RH. The organic fraction in the PM is dominated by the larger polyols, 1,2,5,8-octanetetrol and 1,2,10-decanetriol, especially at RH below $90 \%$, while 1,6-hexanediol, and for the most part also glycerol, partition predominantly to the gas phase. The onset RH of the liquid-liquid phase separation compares well with that of 1,2,5,8-octanetetrol in the ternary water + 1,2,5,8-octanetetrol $+\left(\mathrm{NH}_{4}\right)_{2} \mathrm{SO}_{4}$ mixture at the same salt content, shown in Fig. 6, and is slightly lower than the phase separation onset in the ternary water + 1,2,10-decanetriol + $\left(\mathrm{NH}_{4}\right)_{2} \mathrm{SO}_{4}$ system. Multiple organic compounds of different hydrophilicity in the solution might therefore lead to a lower onset of the liquid-liquid phase separation at the same ionic concentrations as compared to the highest LLE onset$\mathrm{RH}$ for the corresponding ternary water + polyol + salt systems.

\subsection{Compound-specific LLE and RH effects on gas/particle partitioning}

Figure 9 shows the individual gas/particle partitioning of the organics in terms of effective saturation concentrations $C_{j}^{*}$ and the different gas and particle phase terms of Eq. (24). Note that the abscissa label "equil. RH" refers to the RH in equilibrium with the liquid mixture water activity - regardless of whether the liquid mixture is a forced one-phase 

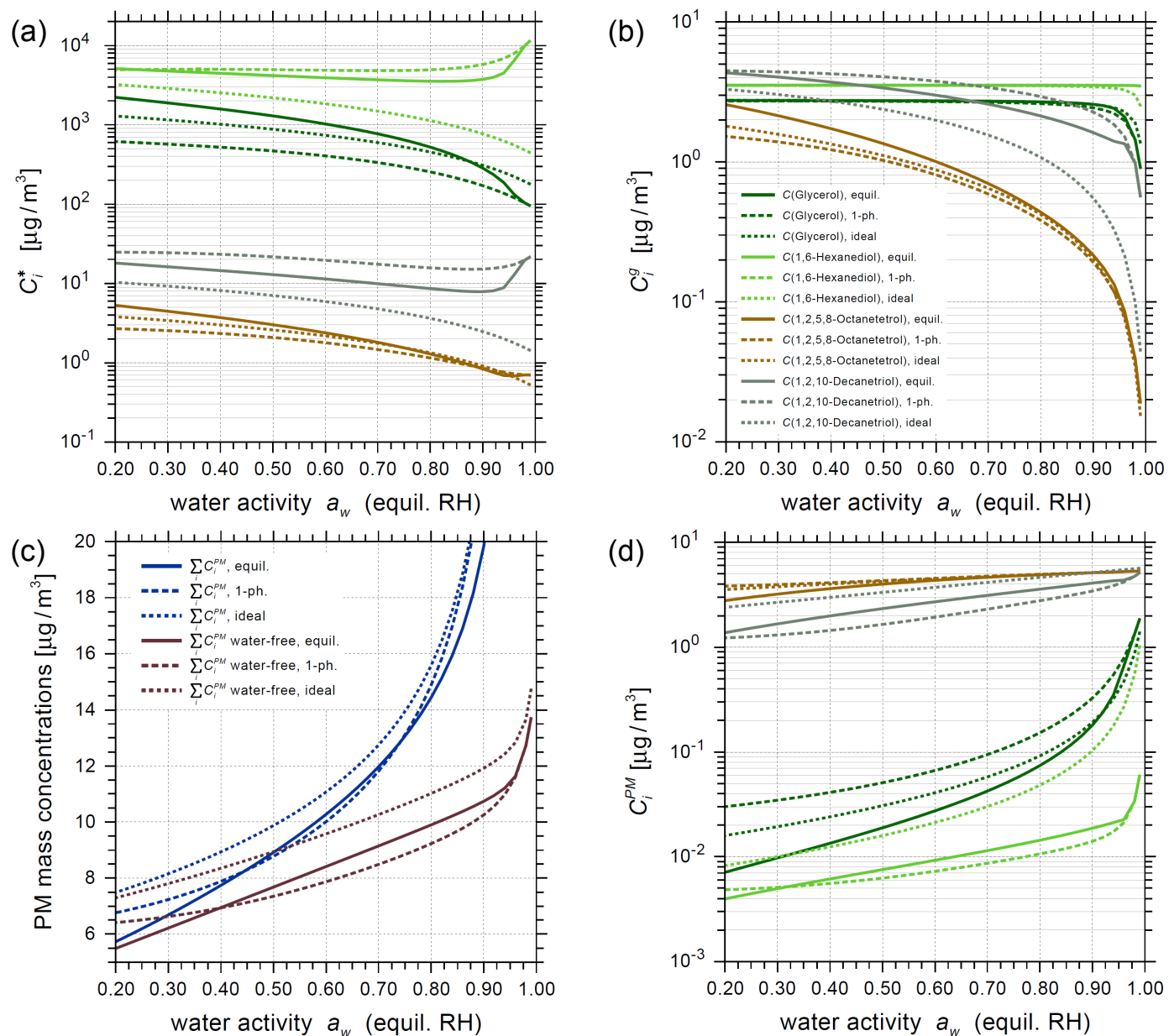

Fig. 9. Mass concentrations of the different semivolatile organics for the three cases of ideal (dotted curves), forced 1-phase (dashed curves) and equilibrium (solid curves) PM mixtures as a function of RH. (a) Effective saturation concentrations $C_{j}^{*}$ (Eq. 24) describing the gas/particle partitioning. Panels (b) and (d) represent corresponding gas and PM mass concentrations. (c) Total PM mass concentration calculated including water or as water-free. Key of (a) and (d) as in (b). Note the different axis scalings.

or the equilibrium case. The six-component system spans a range of organic $C_{j}^{*}$ values from $6 \times 10^{-1}$ up to $10^{4} \mu \mathrm{g} \mathrm{m}^{-3}$. This $C_{j}^{*}$ range, along with an overall O:C ratio of about 0.44 for the organic mixture in the PM, corresponds to the area attributed to organic compounds of intermediate volatility, IVOCs, (1,6-hexanediol) and semivolatile organic compounds, SVOCs, (glycerol, 1,2,5,8-octanetetrol and 1,2,10decanetriol) in the 2-D volatility framework of Jimenez et al. (2009). The calculated O:C ratio is also in good agreement with a mean $\mathrm{O}: \mathrm{C}$ ratio of 0.46 and a range from 0.3 to 0.9 , that was reported by Russell et al. (2009) based on FTIR measurements during the TexAQS/GoMCCS project. The resulting $C_{i}^{*}$ values cover also the range of typical surrogate compounds, for example, those used by Shrivastava et al. (2006) for modelling the partitioning of wood smoke and diesel combustion emissions. For comparisons of the differences concerning the non-ideality treatment in the PM, the gas/particle partitioning results of the equilib- rium, the one-phase, and the ideal liquid mixture calculations are shown. Comparing one-phase and equilibrium calculations, $C_{j}^{*}$ values of the different organics show a compoundspecific partitioning behaviour. The gas/particle partitioning in the case of an ideal liquid mixture is controlled solely by the pure compound vapour pressures. While 1,6-hexanediol and 1,2,10-decanetriol partition more to the gas phase in the one-phase case (below 96\% RH), glycerol and 1,2,5,8octanetetrol show the opposite behaviour. The explanation for the different partitioning behaviour is a result of the difference in hydrophilicity of the compounds, which is also reflected in the different $\mathrm{O}: \mathrm{C}$ ratios. Water-soluble oxygenated organic aerosol (OOA) components feature typically O:C ratios in the range between 1,2,5,8-octanetetrol and glycerol (Jimenez et al., 2009).

Table 2 lists $C_{j}^{*}$ values of the organics at a selection of $\mathrm{RH}$ values in the calculated range. While the absolute values of the $C_{j}^{*}$ are highly compound specific, the ratios of 
Table 2. Variations of $C^{*}$ as a function of RH for an ideal, forced one-phase, and equilibrium PM solution of the organic compounds in the six-component system.

\begin{tabular}{|c|c|c|c|c|c|c|}
\hline \multirow[t]{2}{*}{ RH (\%) } & \multicolumn{3}{|c|}{$C^{*}(1,6$-hexanediol $)\left(\mu \mathrm{g} \mathrm{m}^{-3}\right)$} & \multicolumn{3}{|c|}{$C^{*}($ glycerol $)\left(\mu \mathrm{g} \mathrm{m}^{-3}\right)$} \\
\hline & ideal & 1-phase & equilib. & ideal & 1-phase & equilib. \\
\hline 99 & 445.9 & 11455.5 & 11455.5 & 178.8 & 95.4 & 95.4 \\
\hline 90 & 769.7 & 5769.7 & 3738.8 & 308.7 & 170.8 & 284.2 \\
\hline 80 & 1129.8 & 4943.8 & 3545.3 & 453.1 & 254.6 & 522.8 \\
\hline 70 & 1486.8 & 4820.2 & 3696.1 & 596.3 & 333.8 & 768.8 \\
\hline 60 & 1840.4 & 4872.9 & 3922.9 & 738.2 & 405.4 & 1025.1 \\
\hline 50 & 2190.5 & 4960.4 & 4181.8 & 878.6 & 467.8 & 1295.2 \\
\hline 40 & 2536.7 & 5017.2 & 4462.6 & 1017.4 & 521.7 & 1581.9 \\
\hline 30 & 2879.0 & 5012.5 & 4767.1 & 1154.7 & 569.6 & 1887.4 \\
\hline 20 & 3217.2 & 4944.8 & 5122.1 & 1290.3 & 614.7 & 2222.9 \\
\hline \multirow[t]{2}{*}{$\mathrm{RH}(\%)$} & \multicolumn{3}{|c|}{$C^{*}(1,2,10$-decanetriol $)\left(\mu \mathrm{g} \mathrm{m}^{-3}\right)$} & \multicolumn{3}{|c|}{$C^{*}(1,2,5,8$-octanetetrol $)\left(\mu \mathrm{g} \mathrm{m}^{-3}\right)$} \\
\hline & ideal & 1-phase & equilib. & ideal & 1-phase & equilib. \\
\hline 99 & 1.43 & 21.57 & 21.57 & 0.53 & 0.70 & 0.70 \\
\hline 90 & 2.47 & 15.17 & 7.87 & 0.91 & 0.85 & 0.83 \\
\hline 80 & 3.62 & 15.70 & 8.60 & 1.33 & 1.15 & 1.29 \\
\hline 70 & 4.77 & 17.44 & 9.91 & 1.76 & 1.46 & 1.80 \\
\hline 60 & 5.90 & 19.54 & 11.36 & 2.17 & 1.78 & 2.38 \\
\hline 50 & 7.02 & 21.60 & 12.90 & 2.59 & 2.08 & 3.01 \\
\hline 40 & 8.13 & 23.29 & 14.50 & 3.00 & 2.33 & 3.70 \\
\hline 30 & 9.23 & 24.35 & 16.18 & 3.40 & 2.54 & 4.45 \\
\hline 20 & 10.32 & 24.71 & 18.06 & 3.80 & 2.69 & 5.29 \\
\hline
\end{tabular}

$\operatorname{maximum}\left(C_{j}^{*}\right) / \operatorname{minimum}\left(C_{j}^{*}\right)$ values (max $\left./ \min \right)$, in the considered RH range, are comparable for the different compounds, as shown in Table 3 . The magnitude of this ratio represents the RH-dependency of $C_{j}^{*}$ for a specific compound. In the ideal case, a factor of 7.2 in $C_{j}^{*} \max / \mathrm{min}$ variation is found for all compounds. The max/min ratios in the onephase and equilibrium cases are on the same order as the ideal case ratio or smaller ( $C_{j}^{*} \mathrm{max} / \mathrm{min}$ ratios of 1.6 to 7.6 ), with the exception of glycerol, where in the equilibrium case a max/min factor of 23.3 shows a much higher dependency on $\mathrm{RH}$.

It is of interest to compare the definition of $C_{j}^{*}$, which includes water and other inorganics in the absorbing phase normalisation term (Eq. 24), with the $C_{j}^{*}$ values based solely on the absorption into the organic phase, denoted here as $C_{j}^{*, \mathrm{OA}}$ (Eq. 23). The latter is used in the volatility basis set (VBS) method for describing gas/particle partitioning of (unresolved) organic compounds (Donahue et al., 2006; Robinson et al., 2007). Table 3 compares the $\mathrm{max} / \mathrm{min}$ ratios for the two different $C_{j}^{*}$ definitions considering the $\mathrm{RH}$ range from $20 \%$ to $99 \%$. Overall, the variability of $C_{j}^{*, \mathrm{OA}}$ values is higher than that of $C_{j}^{*}$, in case of the hydrophilic compounds by an order of magnitude. Concerning less hydrophilic organics, the difference in the ratios is about a factor of 2 to 7 for the equilibrium and one-phase cases. In the case of an ideal mixture, the max/min ratio of $C_{j}^{*, \mathrm{OA}}$ is at 77.9 about 10 times larger than the ratio of 7.2 for $C_{j}^{*}$. In case of a LLE, it makes sense to normalise the absorption into an organic phase by the total amount of OA. At RH above 90\%, however, water is highly abundant in mixed organic-inorganic aerosols, and absorption occurs mainly into an aqueous organic solvent mixture rather than into a hydrophobic organic solution, especially when no LLE is present. Thus, at such high RH conditions, water needs to be included in the normalisation term. The predicted dependency of hydrophilic organic PM on $\mathrm{RH}$ at elevated levels $(\mathrm{RH}>70 \%)$ is qualitatively in good agreement with the experimental findings of Hennigan et al. (2008) for water soluble organics. Smog chamber experiments on secondary organic aerosol from $\alpha$ pinene $+\mathrm{O}_{3}$ oxidation products show only modest mass increase at enhanced humidity (Prisle et al., 2010). This modest RH-dependency is consistent with our equilibrium case prediction for less hydrophilic organics. Hence, the degree of RH-dependency varies from system to system governed by the hydrophilicity distribution of the organic aerosol compounds. Comparison of the two effective saturation concentration definitions shows that including the inorganics reduces the variability significantly. As chemical transport models use constant $C_{j}^{*}$ partitioning parameters for lumped organic species or with the VBS method, it is expedient to choose an expression for $C_{j}^{*}$ with a low RH dependency. 
Table 3. Ratios of the maximum/minimum values of $C_{j}^{*}$, OA and of $C_{j}^{*}$, calculated from Eqs. (23) and (24), respectively, in the RH range from $20 \%$ to $99 \%$. The max/min ratios represent the RH-dependency of the two different $C_{j}^{*}$ equilibrium coefficient definitions in the considered range.

\begin{tabular}{lrrrrrrr}
\hline \multirow{2}{*}{ organic compound } & \multicolumn{3}{c}{$C^{*, \mathrm{OA}}$ max/min ratio } & & \multicolumn{3}{c}{$C^{*}$ max/min ratio } \\
\cline { 2 - 4 } \cline { 7 - 8 } & ideal & 1-phase & equilib. & & ideal & 1-phase & equilib. \\
\hline 1,6-hexanediol & 77.9 & 5.2 & 5.2 & & 7.2 & 2.4 & 3.2 \\
glycerol & 77.9 & 77.0 & 269.0 & & 7.2 & 6.4 & 23.3 \\
1,2,10-decanetriol & 77.9 & 13.7 & 9.8 & & 7.2 & 1.6 & 2.7 \\
1,2,5,8-octanetetrol & 77.9 & 45.9 & 87.3 & & 7.2 & 3.8 & 7.6 \\
\hline
\end{tabular}
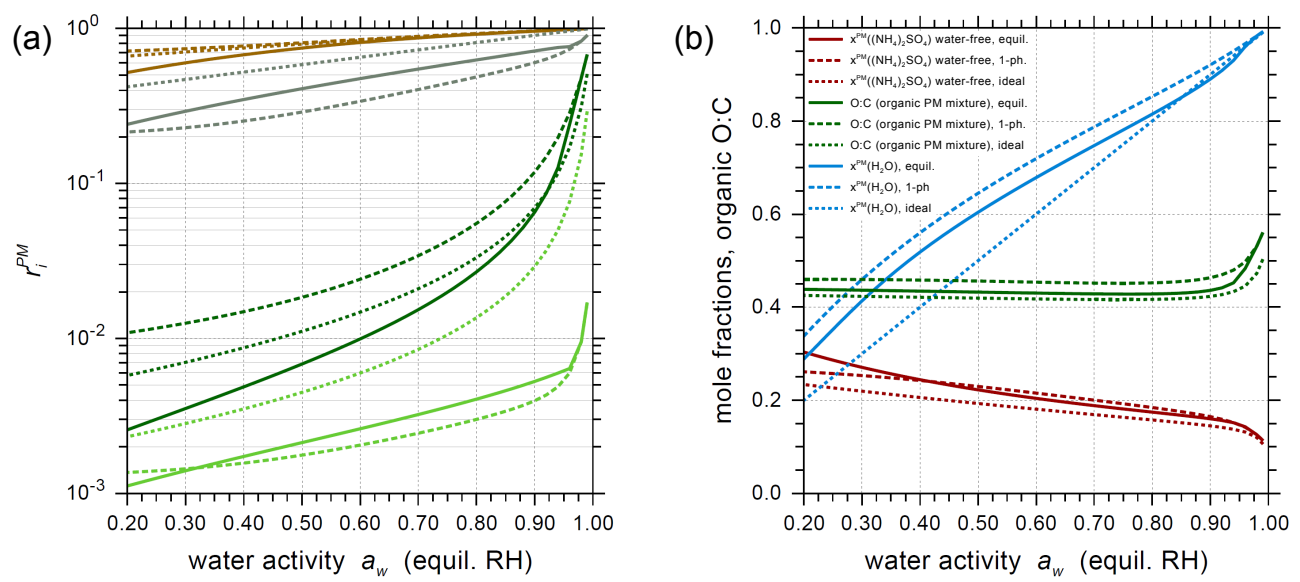

Fig. 10. (a) Gas/particle partitioning for the three cases of ideal, forced 1-phase, and equilibrium PM mixtures in terms of molar PM phase fractions $r_{j}^{\mathrm{PM}}=n_{j}^{\mathrm{PM}} /\left(n_{j}^{\mathrm{PM}}+n_{j}^{g}\right)$ of the different organic compounds. Key as in Fig. 9b. (b) Overall PM mole fractions of ammonium sulphate and water, and $\mathrm{O}: \mathrm{C}$ (atomic ratio) of the organic mixture in the PM phase for the three cases.

Panel (c) of Fig. 9, and more clearly Fig. 10b, shows that the predicted PM water content is higher in the one-phase case than in the equilibrium case. This is true for the entire $\mathrm{RH}$ range in which the one-phase and equilibrium cases differ. Along with a higher water content in the one-phase case, more of the hydrophilic glycerol and 1,2,5,8-octanetetrol are predicted to be dissolved in the PM, while for the less hydrophilic species the salting-out effect caused by the dissolved ammonium and sulphate ions dominates and leads to a partitioning favouring the gas phase. For the hydrophilic organics, water acts like a moderating solvent between dissolved ions and the organic functional groups (hydration effect). With the given total system composition, panel (c) of Fig. 9 shows that above 40\% RH, the LLE leads to a higher water-free PM mass than the one-phase case. However, treating the condensed phase as an ideal solution produces even higher amounts of PM, as the contributions of 1,6-hexanediol and 1,2,10-decanetriol to the PM are highly increased. Increasing the total system amount of rather hydrophilic compounds with O:C ratios around and above 0.5 (glycerol, 1,2,5,8-octanetetrol) can even cause a decrease in PM mass due to liquid-liquid phase separation, as compared to a one-phase aerosol. We performed calculations that show such behaviour for different compositions. It is also the case for the six-component mixture at relative humidities below $40 \%$.

Despite the common assumption that phase separation leads to an increase in organic PM due to increased partitioning of hydrophobic organics to the organic-rich phase, the present calculations clearly show that, along with a decreasing PM water content, hydrophilic species partition preferentially to the gas phase and that the net effect of both opposing trends determines the phase separation effect on the total PM as a function of the system composition. Table 4 presents the water-free PM mass concentrations that are calculated for the three different cases at a number of relative humidities. Considering the whole RH range, the ideal mixture PM mass is $7 \%$ to $33 \%$ higher than in the equilibrium case. Comparing one-phase and equilibrium cases, the deviations range from $-7 \%$ to $+17 \%$ in PM mass. Increasing the salt content of the system can lead to much higher deviations in PM, especially once the majority of organic compounds are salted-out to the gas phase in the one-phase case. 
Table 4. Comparison of the water-free PM mass concentrations resulting for an ideal, forced one-phase, and equilibrium PM solution of the six-component system.

\begin{tabular}{lrrrrrrr}
\hline \multirow{2}{*}{ RH (\%) } & \multicolumn{7}{c}{ water-free PM mass concentration $\left(\mu \mathrm{g} \mathrm{m}^{-3}\right)$} \\
\cline { 2 - 8 } & \multicolumn{2}{c}{ ideal $^{\mathrm{a}}$} & \multicolumn{2}{c}{ 1-phase $^{\mathrm{a}}$} & equilib. total PM & equilib. phase $\alpha$ & equilib. phase $\beta$ \\
\hline 99 & 14.733 & $(+7.4 \%)$ & 13.714 & $(0.0 \%)$ & 13.714 & 6.857 & 6.857 \\
90 & 11.918 & $(+11.0 \%)$ & 10.253 & $(-4.5 \%)$ & 10.739 & 1.320 & 9.419 \\
80 & 11.018 & $(+11.3 \%)$ & 9.228 & $(-6.8 \%)$ & 9.897 & 1.311 & 8.587 \\
70 & 10.263 & $(+12.2 \%)$ & 8.487 & $(-7.2 \%)$ & 9.145 & 1.313 & 7.832 \\
60 & 9.576 & $(+13.9 \%)$ & 7.867 & $(-6.5 \%)$ & 8.409 & 1.314 & 7.095 \\
50 & 8.940 & $(+16.5 \%)$ & 7.349 & $(-4.3 \%)$ & 7.676 & 1.316 & 6.361 \\
40 & 8.349 & $(+20.2 \%)$ & 6.936 & $(-0.1 \%)$ & 6.944 & 1.317 & 5.628 \\
30 & 7.801 & $(+25.5 \%)$ & 6.627 & $(+6.6 \%)$ & 6.214 & 1.318 & 4.897 \\
20 & 7.292 & $(+32.9 \%)$ & 6.409 & $(+16.8 \%)$ & 5.488 & 1.318 & 4.170 \\
\hline
\end{tabular}

a In brackets the relative deviation of the total water-free PM mass with respect to the corresponding equilibrium case.

Figure 10a represents the gas/particle partitioning in terms of the molar PM phase fraction $r_{j}^{\mathrm{PM}}$. The strong RH dependency of the hydrophilic glycerol reflects the nonlinear decrease in PM water content with decreasing RH. Despite the similar pure compound vapour pressures of 1,6-hexanediol and glycerol, the difference in hydrophilicity makes glycerol a semivolatile compound (at least above 60\% RH). Figures 9 and 10 show that the decrease in total PM with decreasing RH is caused mainly by increased partitioning of the hydrophilic organics to the gas phase due to the loss in PM water. Along with that direct RH effect, the shrinking organicrich phase leads as well to a decrease in the less hydrophilic organics while the overall O:C ratio stays almost constant. As hydrophilic organics are still a better solvent than water for the less hydrophilic (and hydrophobic) organics, partitioning of less hydrophilic compounds depends more on the amount of the other organics than on the water content. Therefore, partitioning of less hydrophilic compounds is indirectly influenced by changes in RH. The steep increase in PM water content above $90 \%$ RH predominantly affects the uptake of the more hydrophilic compounds leading to an overall higher O:C ratio in the PM mixture. But again, this also indirectly enhances the PM amount of the less hydrophilic compounds, 1,6-hexanediol and 1,2,10-decanetriol.

Overall PM mole fractions of ammonium sulphate shown in Fig. 10b exhibit an increase with decreasing RH. In the equilibrium case, this overall PM mole fraction calculation includes also the virtually salt-free PM phase $\beta$. Consequently, the increase of ammonium sulphate mole fraction in phase $\alpha$ alone is even higher than the curve suggests. The lower overall salt mole fractions in the one-phase case below $40 \%$ RH is consistent with the higher total PM mass in the one-phase case at those relative humidities. Compared to the ideal case, the water content at $\mathrm{RH}<80 \%$ in both the forced one-phase and the equilibrium calculations is significantly higher. The non-ideality in the mixture, especially the salting-out effect of the ions on the organics, is moderated by water as a common solvent. This is the reason why the PM water content is higher when non-ideality is considered, as the salting-out interactions indirectly also affect water activity. This explains the almost constant difference in $x_{\mathrm{H}_{2} \mathrm{O}}^{\mathrm{PM}}$ between the one-phase and the equilibrium calculations: more water is needed to maintain equilibrium at a given $\mathrm{RH}$ in the one-phase case, as the ion-organic interactions are not moderated by a phase separation.

\section{Conclusions}

Motivated by various applications of thermodynamic phase separation calculations for complementing or simulating laboratory systems and LLE effects on gas/particle partitioning of aerosols, a LLE and gas/particle partitioning model is developed. Based on the non-ideality treatment using the AIOMFAC model, this thermodynamically consistent modelling framework enables the reliable computation of phase separations in binary, ternary, and multicomponent organicinorganic mixtures. The group-contribution concept provides the capability for simulating organic-inorganic mixtures, consisting of the functional groups and ions parametrized in AIOMFAC. The phase separation and gas/particle partitioning modules can also be linked to other activity coefficient models. A further capability of the model is the possibility to calculate thermodynamic properties such as system stability in regions of the phase diagram that are important for natural or technical aerosols but virtually inaccessible experimentally. With regard to the presented model approach, a next step involves amending the AIOMFAC model by further functional groups, such as carboxyl, carbonyl, ester, and aromatic groups.

The phase diagram calculations presented here for alcohol/polyol-water-salt mixtures suggest that liquidliquid phase equilibria are a prevalent feature of mixed 
organic-inorganic aerosol systems owing to strong ionorganic functional group interactions. Depending on the saltconcentration and hydrophilicity of the organics, phase separations can occur at relative humidities even above $90 \%$.

Gas/particle partitioning theory allows computation of the nonlinear coupling of all species and phases in a gas-aerosol system. Using a six-component polyol-water-ammonium sulphate test system, calculations clearly show that the individual partitioning behaviour of organic compounds is affected by the presence of a liquid-liquid phase separation. $\mathrm{RH}$, salt concentration, and hydrophilicity (water-solubility) play a major role in defining the region of a miscibility gap and govern the extent to which compound partitioning is affected by changes in RH. The six-component system further indicates that changes in water concentration directly affect the gas/particle partitioning of hydrophilic organics, which in turn influence the partitioning of less hydrophilic compounds. In this way, the impact from changes in RH is passed from hydrophilic on to hydrophobic compounds in a cascade-like manner. This could be an important process for tropospheric aerosols where a complex mixture of organics ranging from hydrophilic to hydrophobic compounds is likely present in the same phase. Jimenez et al. (2009) suggest that the $\mathrm{O}: \mathrm{C}$ atomic ratio of organic compounds can be used as a proxy for hygroscopicity/hydrophilicity. This is corroborated by results for the six-component polyol-waterammonium sulphate system.

In contrast to the view that liquid-liquid phase separation leads to enhanced partitioning of organics to the particulate phase, in comparison to a one-phase assumption, this study shows that either an increase or decrease of the PM mass is possible, depending on the overall composition of the system and the PM water content.

In consideration of the gas/particle partitioning predictions for the six-component polyol-water-ammonium sulphate system, neglecting non-ideality in the liquid particulate phase leads to an overestimation of total PM mass of up to $30 \%$. Apart from the effect on total PM, assuming an ideal mixture leads also to the prediction of a different PM composition. Individual organic compounds partition in the ideal case only as a function of their pure compound vapour pressures and the vapour pressures of the other semivolatile components, ignoring the demonstrated effect of compoundspecific hydrophilicity. Hence, treating the aerosol phase as an ideal liquid mixture in chemical transport models will also affect reaction yields of simulated liquid-phase chemistry. Furthermore, if potential liquid-liquid phase separation is not taken into account, a forced one-phase solution might spuriously lead to an externally mixed aerosol or a gas-phase enrichment.

The complexity of a detailed gas/particle partitioning description is accompanied by computational demands. Implementation of the gas/particle partitioning model into chemical transport models will lead to high computational costs. The rigorous thermodynamic model is suited as a benchmark model for constructing computationally less expensive, simplified complexity approaches. Furthermore, the model is well-suited to simulate and interpret laboratory experiments.

As an outcome of the six-component system simulation, a modified $C_{j}^{*}$ definition including water and other inorganics in the absorbing phase (Eq. 24) is preferred for implementation in chemical transport models. With no additional computational costs, this $C_{j}^{*}$ definition reduces the $\mathrm{RH}-$ dependency of the gas/particle partitioning of semivolatile organics in organic-inorganic aerosols by an order of magnitude as compared to $C_{j}^{*, \mathrm{OA}}$, which considers the organic species only (Donahue et al., 2006). Using the proposed $C_{j}^{*}$ expression for temperature dependent compound- or surrogate-specific coefficients in simplified partitioning descriptions should significantly improve the gas/particle partitioning representation with respect to changes in relative humidity.

Despite advances in measurement techniques, because of the variety and chemical complexity of the atmospheric organic aerosol, a major fraction of the ambient aerosol is unresolved. This represents a challenge for modelling the gas/particle partitioning of actual aerosol systems. In an attempt to close this gap between technically measurable quantities and a thermodynamically consistent description of the atmospheric aerosol, future work is required to integrate the type of data available from different aerosol instruments. This includes a representation of measured volatility distributions, the mapping of information from AMS spectra, such as $\mathrm{O}: \mathrm{C}$ ratios, covering the range of typical functional groups reported by FTIR analysis, and predicting consistent gas- and particle-phase concentrations, all in a unifying framework.

\section{Appendix A}

\section{Global optimization method}

We use the Differential Evolution (DE) algorithm by Storn and Price (1997), a simple, efficient and robust method for global optimization. The DE code is available in various programming languages at: http://www.icsi.berkeley. edu/ $\sim$ storn/code.html. As the Differential Evolution method is an evolution strategy type of a probabilistic optimization algorithm, it does not need first and second derivatives of the objective function to be computed during optimization. On the other hand, often a large number of objective function evaluations are essential for convergence, which can be computationally expensive. The DE method has been shown to be very successful in escaping from local minima and also not highly sensitive to specific optimization parameter settings or a good initial guess, making it robust and useful for the optimization of multidimensional problems (e.g., Srinivas and Rangaiah, 2007). Based on the Fortran90 Differential Evolution version by Feng-Sheng Wang (available from the website above), we applied in our DE 
code some modifications to speed up phase equilibria calculations. Following the idea of Tvrdik (2006), convergence speed and robustness were improved using competitive parameter settings for the DE parameters $F$ and CR. We implemented the strategy called DEBEST by Tvrdik (2006) with a mutant vector composed of the 25 different combinations from the parameter sets $F=[0.3,0.5,0.8,0.9,1.0]$ and $\mathrm{CR}=[0.1,0.3,0.5,0.8,1.0]$. The $\mathrm{DE}$ algorithm is terminated when a number of $\operatorname{dim} \times$ ntc iterations resulted in no further improvement of the objective function. Here dim denotes the number of dimensions (number of components) and ntc, a termination criterion. The algorithm is run in two modes: (i) a quick mode with ntc $=6$ was set up for fast computations with a DE population size of $N_{\text {pop }}=\operatorname{MIN}(12 \times \operatorname{dim}, 200)$ and (ii) a more robust, but slower high precision mode with ntc $=18$ and $N_{\text {pop }}=\operatorname{MIN}(60 \times \operatorname{dim}, 300)$.

In addition to the Differential Evolution algorithm we use the modified Powell hybrid method and the LevenbergMarquardt method from the Fortran MINPACK library (Moré et al., 1980, 1984) for solving systems of nonlinear equations. The system of nonlinear equations is in this case the set of isoactivity conditions for the two liquid phases, Eq. (9), as a function of $q_{j}^{\alpha}$. The MINPACK methods converge much faster to a minimum (or root) than DE, but they only find the local minimum close to the initial guess. They also inherently converge to a trivial solution when no better two-phase system solution is "downhill" nearby. When the DE algorithm in quick mode finds a two-phase equilibrium, due to the quick mode termination criterion, DE often stops before fully converging to the global Gibbs energy minimum. Therefore, we use Powell's hybrid method and the Levenberg-Marquardt algorithm to further improve the solution found upon DE termination. With this algorithm combination, the global minimum of Gibbs energy is most often found with Eq. $(9)$ fulfilled to machine precision $\left(\approx 10^{-15}\right)$ while running DE in quick mode. However, to reliably detect the onset of the phase separation (the binodal curve), we use a combination with the high precision mode as described in Sect. 2.4.1.

Acknowledgements. This work was supported by Swiss National Science Foundation (SNF) under project no. PA00P2_126227 and the Competence Center Environment and Sustainability of the ETH Domain (CCES) project IMBALANCE. This work was also supported by the Office of Science (BER), US Department of Energy Grant DE-FG02-05ER63983, by US Environmental Protection Agency STAR Research Assistance Agreement RD833749, and the Electric Power Research Institute. This work has not been formally reviewed by the EPA. The view expressed in this publication are solely those of the authors.

Edited by: G. McFiggans

\section{References}

Amundson, N. R., Caboussat, A., He, J. W., Martynenko, A. V., Landry, C., Tong, C., and Seinfeld, J. H.: A new atmospheric aerosol phase equilibrium model (UHAERO): organic systems, Atmos. Chem. Phys., 7, 4675-4698, doi:10.5194/acp-7-46752007, 2007a.

Amundson, N. R., Caboussat, A., He, J. W., Martynenko, A. V., and Seinfeld, J. H.: A phase equilibrium model for atmospheric aerosols containing inorganic electrolytes and organic compounds (UHAERO), with application to dicarboxylic acids, J. Geophys. Res. Atmos., 112, D24S13, doi:10.1029/ 2007JD008424, 2007b.

Apelblat, A. and Korin, E.: The vapour pressures of saturated aqueous solutions of sodium chloride, sodium bromide, sodium nitrate, sodium nitrite, potassium iodate, and rubidium chloride at temperatures from $227 \mathrm{~K}$ to $323 \mathrm{~K}$, J. Chem. Thermodyn., 30, 59-71, 1998.

Aumont, B., Szopa, S., and Madronich, S.: Modelling the evolution of organic carbon during its gas-phase tropospheric oxidation: development of an explicit model based on a self generating approach, Atmos. Chem. Phys., 5, 2497-2517, doi:10.5194/acp-52497-2005, 2005.

Barley, M., Topping, D. O., Jenkin, M. E., and McFiggans, G.: Sensitivities of the absorptive partitioning model of secondary organic aerosol formation to the inclusion of water, Atmos. Chem. Phys., 9, 2919-2932, doi:10.5194/acp-9-2919-2009, 2009.

Barley, M. H. and McFiggans, G.: The critical assessment of vapour pressure estimation methods for use in modelling the formation of atmospheric organic aerosol, Atmos. Chem. Phys., 10, 749767, doi:10.5194/acp-10-749-2010, 2010.

Barsanti, K. C. and Pankow, J. F.: Thermodynamics of the formation of atmospheric organic particulate matter by accretion reactions-Part 1: aldehydes and ketones, Atmos. Environ., 38, 4371-4382, doi:10.1016/j.atmosenv.2004.03.035, http: //www.sciencedirect.com/science/article/B6VH3-4CP67MX-1/ 2/621c9759ec9aac489a28338485deaef4, 2004.

Bowman, F. M. and Melton, J. A.: Effect of activity coefficient models on predictions of secondary organic aerosol partitioning, J. Aerosol Sci., 35, 1415-1438, doi:10.1016/j.jaerosci.2004.07. 001, 2004.

Brenner, D. K., Anderson, E. W., Lynn, S., and Prausnitz, J. M.: Liquid-liquid equilibria for saturated aqueous-solutions of sodium-sulfate plus 1-propanol, 2-propanol, or 2-methylpropan2-ol, J. Chem. Eng. Data, 37, 419-422, 1992.

Cahn, J. W.: Phase Separation by Spinodal Decomposition in Isotropic Systems, J. Chem. Phys., 42, 93-99, doi:10.1063/1. 1695731, 1965.

Camredon, M. and Aumont, B.: Assessment of vapor pressure estimation methods for secondary organic aerosol modeling, Atmos. Environ., 40, 2105-2116, doi:10.1016/j.atmosenv. 2005.11.051, http://www.sciencedirect.com/science/article/ B6VH3-4J32HGG-1/2/571a0401112ea781fedff7b196911ef5, 2006.

Chan, M. N. and Chan, C. K.: Hygroscopic Properties of Two Model Humic-like Substances and Their Mixtures with Inorganics of Atmospheric Importance, Environ. Sci. Technol., 37, 5109-5115, doi:10.1021/es034272o, 2003.

Chang, E. I. and Pankow, J. F.: Prediction of activity coefficients in liquid aerosol particles containing organic compounds, dissolved 
inorganic salts, and water - Part 2: Consideration of phase separation effects by an X-UNIFAC model, Atmos. Environ., 40, 6422-6436, doi:10.1016/j.atmosenv.2006.04.031, 2006.

Chang, E. I. and Pankow, J. F.: Organic particulate matter formation at varying relative humidity using surrogate secondary and primary organic compounds with activity corrections in the condensed phase obtained using a method based on the Wilson equation, Atmos. Chem. Phys., 10, 5475-5490, doi:10.5194/acp-105475-2010, 2010.

Choi, M. Y. and Chan, C. K.: The Effects of Organic Species on the Hygroscopic Behaviors of Inorganic Aerosols, Environ. Sci. Technol., 36, 2422-2428, doi:10.1021/es0113293, 2002.

Ciobanu, V. G., Marcolli, C., Krieger, U. K., Weers, U., and Peter, T.: Liquid-Liquid Phase Separation in Mixed Organic/Inorganic Aerosol Particles, J. Phys. Chem. A, 113, 10966-10978, doi:10. 1021/jp905054d, 2009.

Clegg, S. L., Seinfeld, J. H., and Brimblecombe, P.: Thermodynamic modelling of aqueous aerosols containing electrolytes and dissolved organic compounds, J. Aerosol. Sci., 32, 713-738, 2001.

Clegg, S. L., Kleeman, M. J., Griffin, R. J., and Seinfeld, J. H.: Effects of uncertainties in the thermodynamic properties of aerosol components in an air quality model - Part 1: Treatment of inorganic electrolytes and organic compounds in the condensed phase, Atmos. Chem. Phys., 8, 1057-1085, doi:10.5194/acp-81057-2008, 2008.

Cocker, D. R., Clegg, S. L., Flagan, R. C., and Seinfeld, J. H.: The effect of water on gas-particle partitioning of secondary organic aerosol. Part I: $\alpha$-pinene/ozone system, Atmos. Environ., 35, 6049-6072, 2001.

De Santis, R., Marrelli, L., and Muscetta, P. N.: Liquid-liquid equilibria in water-aliphatic alcohol systems in the presence of sodium chloride, Chem. Eng. J., 11, 207-214, 1976.

Debenedetti, P. G.: Metastable Liquids. Concepts and Principles, Princeton Univ. Press, Princeton, NJ, USA, 1996.

Decesari, S., Facchini, M. C., Fuzzi, S., and Tagliavini, E.: Characterization of water-soluble organic compounds in atmospheric aerosol: A new approach, J. Geophys. Res. Atmos., 105, 14811489, doi:10.1029/1999JD900950, 2000.

Decesari, S., Fuzzi, S., Facchini, M. C., Mircea, M., Emblico, L., Cavalli, F., Maenhaut, W., Chi, X., Schkolnik, G., Falkovich, A., Rudich, Y., Claeys, M., Pashynska, V., Vas, G., Kourtchev, I., Vermeylen, R., Hoffer, A., Andreae, M. O., Tagliavini, E., Moretti, F., and Artaxo, P.: Characterization of the organic composition of aerosols from Rondônia, Brazil, during the LBASMOCC 2002 experiment and its representation through model compounds, Atmos. Chem. Phys., 6, 375-402, doi:10.5194/acp6-375-2006, 2006.

Denbigh, K. G.: The principles of chemical equilibrium, Cambridge University Press, Cambridge, UK, 4th edn., 1981.

Donahue, N. M., Robinson, A. L., Stanier, C. O., and Pandis, S. N.: Coupled Partitioning, Dilution, and Chemical Aging of Semivolatile Organics, Environ. Sci. Technol., 40, 2635-2643, doi:10.1021/es052297c, 2006.

Dykyj, J., Svoboda, J., Wilhoit, R. C., Frenkel, M., and Hall, K. R.: Organic Compounds, C1 to C57. Part 1., in: Landolt-Börnstein - Group IV Physical Chemistry Numerical Data and Functional Relationships in Science and Technology, edited by: Hall, K. R., vol. 20B: Vapor Pressure and Antoine Constants for Oxygen
Containing Organic Compounds, 14-110, SpringerMaterials The Landolt-Börnstein Database, doi:10.1007/10688583_3, http: //www.springermaterials.com, 2000.

Erdakos, G. B. and Pankow, J. F.: Gas/particle partitioning of neutral and ionizing compounds to single- and multi-phase aerosol particles. 2. Phase separation in liquid particulate matter containing both polar and low-polarity organic compounds, Atmos. Environ., 38, 1005-1013, doi:10.1016/j.atmosenv.2003.10.038, 2004.

Filobelo, L. F., Galkin, O., and Vekilov, P. G.: Spinodal for the solution-to-crystal phase transformation, J. Chem. Phys., 123, ISSN: 0021-9606, doi:10.1063/1.1943413, 2005.

Fredenslund, A., Jones, R. L., and Prausnitz, J. M.: GroupContribution Estimation of Activity Coefficients in Nonideal Liquid Mixtures, AIChE J., 21, 1086-1099, 1975.

Gaffen, D. J., Robock, A., and Elliott, W. P.: Annual Cycles of Tropospheric Water Vapor, J. Geophys. Res., 97, 18185-18193, 1992.

Gibbs, J. W.: The collected works of J. Willard Gibbs. Volume I thermodynamics, Longmans, Green and Co., New York, NY, USA, 1928.

Goldstein, A. H. and Galbally, I. E.: Known and Unexplored Organic Constituents in the Earth's Atmosphere, Environ. Sci. Technol., 41, 1514-1521, 2007.

Gomis, V., Ruiz, F., Devera, G., Lopez, E., and Saquete, M. D.: Liquid-liquid-solid equilibria for the ternary-systems water sodium-chloride or potassium-chloride 1-propanol or 2propanol, Fluid Phase Equilib., 98, 141-147, 1994.

Griffin, R. J., Dabdub, D., and Seinfeld, J. H.: Secondary organic aerosol - 1. Atmospheric chemical mechanism for production of molecular constituents, J. Geophys. Res. Atmos., 107, 4332, doi: 10.1029/2001JD000541, 2002.

Griffin, R. J., Nguyen, K., Dabdub, D., and Seinfeld, J. H.: A Coupled Hydrophobic-Hydrophilic Model for Predicting Secondary Organic Aerosol Formation, J. Atmos. Chem., 44, 171190, 2003.

Hallquist, M., Wenger, J. C., Baltensperger, U., Rudich, Y., Simpson, D., Claeys, M., Dommen, J., Donahue, N. M., George, C., Goldstein, A. H., Hamilton, J. F., Herrmann, H., Hoffmann, T., Iinuma, Y., Jang, M., Jenkin, M. E., Jimenez, J. L., Kiendler-Scharr, A., Maenhaut, W., McFiggans, G., Mentel, Th. F., Monod, A., Prév^t, A. S. H., Seinfeld, J. H., Surratt, J. D., Szmigielski, R., and Wildt, J.: The formation, properties and impact of secondary organic aerosol: current and emerging issues, Atmos. Chem. Phys., 9, 5155-5236, doi:10.5194/acp-95155-2009, 2009.

Hennigan, C. J., Bergin, M. H., Dibb, J. E., and Weber, R. J.: Enhanced secondary organic aerosol formation due to water uptake by fine particles, Geophys. Res. Lett., 35(18), L18801, doi: 10.1029/2008GL035046, 2008.

Herrmann, H., Tilgner, A., Barzaghi, P., Majdik, Z., Gligorovski, S., Poulain, L., and Monod, A.: Towards a more detailed description of tropospheric aqueous phase organic chemistry: CAPRAM 3.0, Atmos. Environ., 39, 4351-4363, doi:10.1016/j.atmosenv.2005. 02.016, 2005.

Jimenez, J. L., Canagaratna, M. R., Donahue, N. M., Prevot, A. S. H., Zhang, Q., Kroll, J. H., DeCarlo, P. F., Allan, J. D., Coe, H., Ng, N. L., Aiken, A. C., Docherty, K. S., Ulbrich, I. M., Grieshop, A. P., Robinson, A. L., Duplissy, J., Smith, J. D., 
Wilson, K. R., Lanz, V. A., Hueglin, C., Sun, Y. L., Tian, J., Laaksonen, A., Raatikainen, T., Rautiainen, J., Vaattovaara, P., Ehn, M., Kulmala, M., Tomlinson, J. M., Collins, D. R., Cubison, M. J., Dunlea, E. J., Huffman, J. A., Onasch, T. B., Alfarra, M. R., Williams, P. I., Bower, K., Kondo, Y., Schneider, J., Drewnick, F., Borrmann, S., Weimer, S., Demerjian, K., Salcedo, D., Cottrell, L., Griffin, R., Takami, A., Miyoshi, T., Hatakeyama, S., Shimono, A., Sun, J. Y., Zhang, Y. M., Dzepina, K., Kimmel, J. R., Sueper, D., Jayne, J. T., Herndon, S. C., Trimborn, A. M., Williams, L. R., Wood, E. C., Middlebrook, A. M., Kolb, C. E., Baltensperger, U., and Worsnop, D. R.: Evolution of Organic Aerosols in the Atmosphere, Science, 326, 1525-1529, doi:10.1126/science.1180353, 2009.

Kalberer, M., Paulsen, D., Sax, M., Steinbacher, M., Dommen, J., Prevot, A. S. H., Fisseha, R., Weingartner, E., Frankevich, V., Zenobi, R., and Baltensperger, U.: Identification of Polymers asMajor Components of Atmospheric Organic Aerosols, Science, 303, 1659-1662, 2004.

Kanakidou, M., Seinfeld, J. H., Pandis, S. N., Barnes, I., Dentener, F. J., Facchini, M. C., Van Dingenen, R., Ervens, B., Nenes, A., Nielsen, C. J., Swietlicki, E., Putaud, J. P., Balkanski, Y., Fuzzi, S., Horth, J., Moortgat, G. K., Winterhalter, R., Myhre, C. E. L., Tsigaridis, K., Vignati, E., Stephanou, E. G., and Wilson, J.: Organic aerosol and global climate modelling: a review, Atmos. Chem. Phys., 5, 1053-1123, doi:10.5194/acp-5-1053-2005, 2005.

Knopf, D. A., Anthony, L. M., and Bertram, A. K.: Reactive Uptake of $\mathrm{O}_{3}$ by Multicomponent and Multiphase Mixtures Containing Oleic Acid, J. Phys. Chem. A, 109, 5579-5589, 2005.

Kroll, J. H. and Seinfeld, J. H.: Chemistry of secondary organic aerosol: Formation and evolution of lowvolatility organics in the atmosphere, Atmos. Environ., 42, 3593-3624, doi:10.1016/j.atmosenv.2008.01.003, http: //www.sciencedirect.com/science/article/B6VH3-4RJK162-1/2/ 9f429e694943ea6a240510087fe93cdb, 2008.

Lee, S. H., Murphy, D. M., Thomson, D. S., and Middlebrook, A. M.: Chemical components of single particles measured with Particle Analysis by Laser Mass Spectrometry (PALMS) during the Atlanta SuperSite Project: Focus on organic/sulfate, lead, soot, and mineral particles, J. Geophys. Res. Atmos., 107, 4003, doi:10.1029/2000JD000011, 2002.

Li, Z. C., Tang, Y. P., Liu, Y., and Li, Y. G.: Salting effect in partially miscible systems of n-butanol water and butanone water .1 . Determination and correlation of liquid-liquid equilibrium data, Fluid Phase Equilib., 103, 143-153, 1995.

Ling, T. Y. and Chan, C. K.: Partial crystallization and deliquescence of particles containing ammonium sulfate and dicarboxylic acids, J. Geophys. Res. Atmos., 113(D14), D14205, doi: 10.1029/2008JD009779, 2008.

Lynn, S., Schiozer, A. L., Jaecksch, W. L., Cos, R., and Prausnitz, J. M.: Recovery of anhydrous $\mathrm{Na}_{2} \mathrm{SO}_{4}$ from $\mathrm{SO}_{2}$-scrubbing liquor by extractive crystallization: Liquid-liquid equilibria for aqueous solutions of sodium carbonate, sulfate, and/or sulfite plus acetone, 2-propanol, or tert-butyl alcohol, Ind. Eng. Chem. Res., 35, 4236-4245, 1996.

Marcilla, A., Olaya, M. M., and Serrano, M. D.: Comments on Liquid-Liquid Equilibrium Data Regression, J. Chem. Eng. Data, 52, 2538-2541, doi:10.1021/je700320u, 2007.
Marcolli, C. and Krieger, U. K.: Phase changes during hygroscopic cycles of mixed organic/inorganic model systems of tropospheric aerosols, J. Phys. Chem. A, 110, 1881-1893, doi: 10.1021/jp0556759, 2006.

Marcolli, C. and Peter, Th.: Water activity in polyol/water systems: new UNIFAC parameterization, Atmos. Chem. Phys., 5, 15451555, doi:10.5194/acp-5-1545-2005, 2005.

Marcolli, C., Luo, B. P., and Peter, T.: Mixing of the Organic Aerosol Fractions: Liquids as the Thermodynamically Stable Phases, J. Phys. Chem. A, 108, 2216-2224, doi:10.1021/ jp0360801, 2004a.

Marcolli, C., Luo, B. P., Peter, Th., and Wienhold, F. G.: Internal mixing of the organic aerosol by gas phase diffusion of semivolatile organic compounds, Atmos. Chem. Phys., 4, 25932599, doi:10.5194/acp-4-2593-2004, 2004b.

Maria, S. F., Russell, L. M., Gilles, M. K., and Myneni, S. C. B.: Organic aerosol growth mechanisms and their climate-forcing implications, Science, 306, 1921-1924, doi:10.1126/science. 1103491, 2004.

Middlebrook, A. M., Murphy, D. M., and Thomson, D. S.: Observations of organic material in individual marine particles at Cape Grim during the First Aerosol Characterization Experiment (ACE 1), J. Geophys. Res. Atmos., 103, 16475-16483, 1998.

Modell, M. and Reid, R. C.: Thermodynamics and Its Applications, Prentice-Hall, Inc., Englewood Cliffs, NJ, USA, 2nd edn., 1983.

Moller, B., Rarey, J., and Ramjugernath, D.: Estimation of the vapour pressure of non-electrolyte organic compounds via group contributions and group interactions, J. Mol. Liq., 143, 52-63, doi:10.1016/j.molliq.2008.04.020, 2008.

Moré, J. J., Garbow, B. S., and Hillstrom, K. E.: User Guide for MINPACK-1, Argonne National Laboratory Report ANL-80-74, Argonne, Ill., USA, http://www.netlib.org/minpack/, 1980.

Moré, J. J., Sorensen, D. C., Hillstrom, K. E., and Garbow, B. S.: The MINPACK Project, in Sources and Development of Mathematical Software, Prentice-Hall, Inc., Upper Saddle River, NJ, USA, 1984.

Murphy, D. M. and Thomson, D. S.: Chemical composition of single aerosol particles at Idaho Hill: Negative ion measurements, J. Geophys. Res. Atmos., 102, 6353-6368, 1997.

Murphy, D. M., Cziczo, D. J., Froyd, K. D., Hudson, P. K., Matthew, B. M., Middlebrook, A. M., Peltier, R. E., Sullivan, A., Thomson, D. S., and Weber, R. J.: Single-particle mass spectrometry of tropospheric aerosol particles, J. Geophys. Res. Atmos., 111, D23S32, doi:10.1029/2006JD007340, 2006.

Nannoolal, Y., Rarey, J., Ramjugernath, D., and Cordes, W.: Estimation of pure component properties Part 1. Estimation of the normal boiling point of non-electrolyte organic compounds via group contributions and group interactions, Fluid Phase Equilib., 226, 45-63, doi:10.1016/j.fluid.2004.09.001, 2004.

Odum, J. R., Hoffmann, T., Bowman, F., Collins, D., Flagan, R. C., and Seinfeld, J. H.: Gas/Particle Partitioning and Secondary Organic Aerosol Yields, Environ. Sci. Technol., 30, 2580-2585, 1996.

Pankow, J. F.: An absorption model of gas/particle partitioning of organic compounds in the atmosphere, Atmos. Environ., 28, 185-188, 1994.

Pankow, J. F.: Gas/particle partitioning of neutral and ionizing compounds to single and multi-phase aerosol particles. 1.Unified modeling framework, Atmos. Environ., 37, 3323-3333, doi: 
10.1016/S1352-2310(03)00346-7, 2003.

Pankow, J. F. and Chang, E. I.: Variation in the Sensitivity of Predicted Levels of Atmospheric Organic Particulate Matter (OPM), Environ. Sci. Technol., 42, 7321-7329, doi:10.1021/es8003377, 2008.

Pankow, J. F., Seinfeld, J. H., Asher, W. E., and Erdakos, G. B.: Modeling the Formation of Secondary Organic Aerosol. 1. Application of Theoretical Principles to Measurements Obtained in the $\alpha$-Pinene/, $\beta$-Pinene/, Sabinene/, $\Delta^{3}$-Carene/, and Cyclohexene/Ozone Systems, Environ. Sci. Technol., 35, 1164-1172, doi: 10.1021/es001321d, 2001.

Pant, A., Fok, A., Parsons, M. T., Mak, J., and Bertram, A. K.: Deliquescence and crystallization of ammonium sulfate-glutaric acid and sodium chloride-glutaric acid particles, Geophys. Res. Lett., 31, L12111, doi:10.1029/2004GL020025, 2004.

Parsons, M. T., Knopf, D. A., and Bertram, A. K.: Deliquescence and Crystallization of Ammonium Sulfate Particles Internally Mixed with Water-Soluble Organic Compounds, J. Phys. Chem. A, 108, 11600-11608, doi:10.1021/jp0462862, 2004.

Pierrehumbert, R. T., Brogniez, H., and Roca, R.: On the Relative Humidity of the Atmosphere, in: The Global Circulation of the Atmosphere, edited by: Schneider, T. and Sobel, A. H., 143-185, Princeton Univ. Press, Princeton, NJ, USA, 2007.

Prisle, N. L., Engelhart, G. J., Bilde, M., and Donahue, N. M.: Humidity influence on gas-particle phase partitioning of $\alpha$-pinene + $\mathrm{O}_{3}$ secondary organic aerosol, Geophys. Res. Lett., 37, L01802, doi:10.1029/2009GL041402, 2010.

Pun, B. K., Griffin, R. J., Seigneur, C., and Seinfeld, J. H.: Secondary organic aerosol -2 . Thermodynamic model for gas/particle partitioning of molecular constituents, J. Geophys. Res. Atmos., 107(D17), 4333, doi:10.1029/2001JD000542, 2002.

Ravishankara, A. R.: Heterogeneous and Multiphase Chemistry in the Troposphere, Science, 276, 1058-1065, doi:10.1126/ science.276.5315.1058, http://www.sciencemag.org/cgi/content/ abstract/276/5315/1058, 1997.

Robinson, A. L., Donahue, N. M., Shrivastava, M. K., Weitkamp, E. A., Sage, A. M., Grieshop, A. P., Lane, T. E., Pierce, J. R., and Pandis, S. N.: Rethinking Organic Aerosols: Semivolatile Emissions and Photochemical Aging, Science, 315, 1259-1262, doi:10.1126/science.1133061, 2007.

Rogge, W. F., Mazurek, M. A., Hildemann, L. M., Cass, G. R., and Simoneit, B. R. T.: Quantification of Urban Organic Aerosols at a Molecular Level Identification, Abundance and Seasonal Variation, Atmos. Environ., 27, 1309-1330, 1993.

Russell, L. M., Takahama, S., Liu, S., Hawkins, L. N., Covert, D. S., Quinn, P. K., and Bates, T. S.: Oxygenated fraction and mass of organic aerosol from direct emission and atmospheric processing measured on the R/V Ronald Brown during TEXAQS/GoMACCS 2006, J. Geophys. Res. Atmos., 114, D00F05, doi:10.1029/2008JD011275, 2009.

Saxena, P. and Hildemann, L.: Water-soluble organics in atmospheric particles: A critical review of the literature and application of thermodynamics to identify candidate compounds, J. Atmos. Chem., 24, 57-109, 1996.

Saxena, P. and Hildemann, L. M.: Water absorption by organics: Survey of laboratory evidence and evaluation of UNIFAC for estimating water activity, Environ. Sci. Technol., 31, 3318-3324, 1997.
Saxena, P., Hildemann, L. M., McMurry, P. H., and Seinfeld, J. H.: Organics alter hygroscopic behavior of atmospheric particles, J. Geophys. Res. Atmos., 100, 18755-18770, 1995.

Saxena, R. and Caneba, G. T.: Studies of Spinodal Decomposition in a Ternary Polymer-Solvent-Nonsolvent System, Polym. Eng. Sci., 42, 1019-1031, 2002.

Seinfeld, J. H. and Pandis, S. N.: Atmospheric Chemistry and Physics: From Air Pollution to Climate Change, J. Wiley \& Sons, New York, USA, 1998.

Seinfeld, J. H., Erdakos, G. B., Asher, W. E., and Pankow, J. F.: Modeling the Formation of Secondary Organic Aerosol (SOA). 2. The Predicted Effects of Relative Humidity on Aerosol Formation in the $\alpha$-Pinene-, $\beta$-Pinene-, Sabinene-, $\Delta^{3}$-Carene-, and Cyclohexene-Ozone Systems, Environ. Sci. Technol., 35, 18061817, doi:10.1021/es001765+, 2001.

Shrivastava, M. K., Lipsky, E. M., Stanier, C. O., and Robinson, A. L.: Modeling Semivolatile Organic Aerosol Mass Emissions from Combustion Systems, Environ. Sci. Technol., 40, 26712677, doi:10.1021/es0522231, 2006.

Speight, J. G. (ed.): LANGES HANDBOOK OF CHEMISTRY, McGraw-Hill Companies, Inc., New York, USA, 16th edn., 2005.

Srinivas, M. and Rangaiah, G. P.: A study of differential evolution and tabu search for benchmark, phase equilibrium and phase stability problems, Comput. Chem. Eng., 31, 760-772, doi:10.1016/j.compchemeng.2006.07.015, 2007.

Storn, R. and Price, K.: Differential Evolution - A Simple and Efficient Heuristic for Global Optimization over Continuous Spaces, J. Global Optim., 11, 341-359, 1997.

Turpin, B. J., Saxena, P., and Andrews, E.: Measuring and simulating particulate organics in the atmosphere: problems and prospects, Atmos. Environ., 34, 2983-3013, 2000.

Tvrdik, J.: Differential Evolution: Competitive Setting of Control Parameters., Proceedings of the International Multiconference on Computer Science and Information Technology, 207-213, 2006.

VonNiederhausern, D. M., Wilson, G. M., and Giles, N. F.: Critical Point and Vapor Pressure Measurements for Four Compounds by a Low Residence Time Flow Method, J. Chem. Eng. Data, 51, 1986-1989, doi:10.1021/je0602465, 2006.

Yamasaki, H., Kuwata, K., and Miyamoto, H.: Effects of Ambient Temperature on Aspects of Airborne Polycyclic Aromatic Hydrocarbons, Environ. Sci. Technol., 16, 189-194, 1982.

Yan, W. D., Topphoff, M., Rose, C., and Gmehling, J.: Prediction of vapor-liquid equilibria in mixed-solvent electrolyte systems using the group contribution concept, Fluid Phase Equilib., 162, 97-113, 1999.

Yu, J. Z., Cocker, D. R., Griffin, R. J., Flagan, R. C., and Seinfeld, J. H.: Gas-phase ozone oxidation of monoterpenes: Gaseous and particulate products, J. Atmos. Chem., 34, 207-258, 1999.

Zhang, Q., Jimenez, J. L., Canagaratna, M. R., Allan, J. D., Coe, H., Ulbrich, I., Alfarra, M. R., Takami, A., Middlebrook, A. M., Sun, Y. L., Dzepina, K., Dunlea, E., Docherty, K., DeCarlo, P. F., Salcedo, D., Onasch, T., Jayne, J. T., Miyoshi, T., Shimono, A., Hatakeyama, S., Takegawa, N., Kondo, Y., Schneider, J., Drewnick, F., Borrmann, S., Weimer, S., Demerjian, K., Williams, P., Bower, K., Bahreini, R., Cottrell, L., Griffin, R. J., Rautiainen, J., Sun, J. Y., Zhang, Y. M., and Worsnop, D. R.: Ubiquity and dominance of oxygenated species in organic aerosols in anthropogenically-influenced Northern Hemi- 
sphere midlatitudes, Geophys. Res. Lett., 34, L13801, doi:10. 1029/2007GL029979, 2007.

Zuend, A.: Modelling the Thermodynamics of Mixed OrganicInorganic Aerosols to Predict Water Activities and Phase Separations, Phd thesis, ETH Zurich, Zurich, Switzerland, doi:10. 3929/ethz-a-005582922, http://e-collection.ethbib.ethz.ch/view/ eth:30457, 2007.
Zuend, A., Marcolli, C., Luo, B. P., and Peter, T.: A thermodynamic model of mixed organic-inorganic aerosols to predict activity coefficients, Atmos. Chem. Phys., 8, 4559-4593, doi:10.5194/acp8-4559-2008, 2008. 